\title{
Quarantined Atmospheres
}

\author{
by \\ Paul Jackson
}

A thesis submitted to the Faculty of Graduate and Postdoctoral Affairs in partial fulfillment of the requirements for the degree of

Master of Architecture

in

Azrieli School of Architecture \& Urbanism

\author{
Carleton University \\ Ottawa, Ontario
}

(C) 2021

Paul Jackson 
This thesis explores how atmospheric isolation contributes to the creation and maintenance of the domestic interior. My contention is that our methods of environmental control are tightly woven with the establishment of domestic social spaces. Increases in the level of atmospheric containment yield tighter barriers against the presence of others. When atmospheres are charged with an epidemiological threat, this process is amplified.

However, social fabrics are strained when these barriers are strengthened. Social topologies are dependent on moments of free exchange and interaction, which diminish as the domestic barrier is strengthened. Conditions and processes outside become increasingly rejected.

This thesis critically reimagines the barriers which maintain spaces of isolation in the domestic context, highlighting the folly of that isolation. This is explored through testing the limits and possibilities of environmental and social porosity in conditions of quarantine.

Throughout the thesis a series of physical architectura models submerged within a tank of water enable visualisation of the mechanisms of atmospheric exchange, illustrate related theoretical concepts, and speculate about interventions.

The thesis culminates in the design of a space of quarantine, composed of four components that blur boundaries around interior spaces and atmospheres, enabling an inhabitation that occupies multiple, shifting relational fields. 
Thank you first to my advisor Lisa, for your tireless support and pushing that helped make this exploration possible. Your passion and insight kept me going when the path ahead was unclear.

Thank you to Sarah for your faith, encouragement, and infinite patience.

Thank you to Ross and Kay for understanding, in your own way, that I was doing something worth doing.

And thank you to my father, Stuart, who tried to talk me out of it.

\section{Acknowledgements}

Introduction

Chapter 1: Interior Isolation

Chapter 2: Collective Isolation

Chapter 3: Filtration

Chapter 4: Quarantine Architecture

Epilogue

Appendix 1: Contact Sheets 


\section{Fluid study}

Light study with flexible membrane. Contact sheet 1.

The Functional House for Frictionless Living by Alexander Klein

Curtain Wall House (Shigeru Ban)

'Lange House Cover' by Haus-Rucker-Co

'Anatomy of a Dwelling' (Francois Dellagret)

'Power Membrane House' (Francois Dellagret)

'The Environment Bubble' (Francois Dellagret)

Containment Study. Contact sheet 7

Case Study: 154 Spruce Contact sheet 10.

Inter-floor flow testing (1/2) Contact sheet 9

Inter-floor flow testing (2/2). Contact sheet 9

Contamination study. Contact sheet 8

View study with layers. Contact sheet 1

Filtration study. Contact sheet 6

Selective control with porous field. Contact sheet 4

Enclosure approximation experiment. Contact Sheet 5

Enclosure approximation experiment (cont'd) Contact Sheet 5.

Selective control with aperture. Contact sheet 5 .

Porous Wall study. Contact Sheet 12.

Zibi 'Kanaal' condo privacy and airflow analysis.

Climactic Analysis
Site Photograph

Building Axonometric

Thermal Attractor Pad Components

Party Wall Components

Chimney Lung Components 
"All contemporary dwellings not only have air conditioning...they are in fact air conditioning systems." Peter Sloterdijk.

This thesis examines reciprocities between social and technical readings of two architectural topologies: the bubble and the filter. When our domestic interiors become better insulated from atmospheric conditions outside, how does that affect our ability to interface with those on the outside? How can we reverse the tendency towards social isolation by calibrating the barriers between inside and outside?

The project begins with an investigation into interior isolation, starting with the historical development of the domestic interior. Chapter One situates the emergence of the private dwelling against the backdrop of industrialization and the differentiation of the home from the workplace. Conceptions of privacy coalesce with newly formed ideals of interior organization. By the middle of the $20^{\text {th }}$ century, climate anxieties - and concomitant shifts in perspective around the place of the human on earth - support conservation-minded attempts at hyper-enclosed systems intended to seal off inhabitants (and their messy by-products) from a natural world which is suddenly acknowledged as finite. The rise of integrated HVAC technologies prompts questions about the role of the building envelope, as universal interior conditions become commonplace. Architectural forms such as bubbles and domes, which reflect philosophies such as Buckminster Fuller's Spaceship Earth, 
emerged as a result. Paradoxically, these architectural strategies rely on sealing off inhabitants from the conditions they intend to preserve.

Chapter Two engages contemporary critical theory concerning the topology of human spatial-social constructions, with a focus on the work of Peter Sloterdijk. Sloterdijk defines the interior as a co-constructed space, where a dyadic selfother condition maintain a defensive position against those on the outside. The 'bubble' metaphor describes the first-order building block of human space - a shifting, overlapping series of boundaries which make up sets of nested spatial conditions. Within this context emerges the central question of the thesis: using the topology of Sloterdijk's concept of the egosphere as a base condition, how can spheres of concern be expanded to include entities and conditions outside the interiority of contemporary dwelling?

Chapter Three surveys an array of approaches to porous building envelopes, opening an inquiry into how such approaches could yield conditions of social porosity. By embracing thermal difference and permitting elements of the inside into the interior, this counter-model pushes against the dominant ethos of generic interiors in favour of an architecture sensitive to the place of the inhabitant with a relational field of dynamic atmospheric and thermal conditions. The bubble is ruptured; the egosphere expanded.

The concluding chapter applies these theoretical readings and material explorations to the design of a building, responding to the question: how, then, to imagine a weakening of the barrier between home and not-home, between inside and outside, between privacy and public-ness? The context for the intervention is an adaptive reuse project on a heritage industrial site in Gatineau, Quebec. The design imagines a residential space for those placed under quarantine who rely on family or community support. Caretakers share space with those under quarantine while carefully managed airflow maintains epidemiological separation. The intimacy of housing - and its formal expression of isolation in high-density North American typologies - make it a ripe space for intervention. The two groups - the quarantined and their loved ones - occupy the building together yet apart, negotiating boundaries of containment and contact, encapsulation, and filtration. 
This posture of defence incurs a cost on multiple scales and in multiple contexts. Failure to acknowledge external conditions further isolates inhabitants from relational fields outside the bubble. Atmospheres are increasingly bifurcated through careful filtration and conditioning, rendering outside air (and the others breathing it) unknown.

The phenomenon of interior isolation is examined here by way of two related concerns: the spatial arrangement of the domestic interior, and the maintenance of interior atmospheres. The following section explores emergence of the domestic interior.

For whom is the interior defined? Without an individual, the interior is without referent. For Walter Benjamin, the individual in Europe makes her appearance in history during the reign of the 'Citizen King' Louis Philippe. During his reign, writes Benjamin, "the private individual makes his entry into history". Through the elevation of the bourgeois and the differentiation of the workplace wrought by industrialization, the home becomes in the $19^{\text {th }}$ century a place of not-work, an insulated place of repose and protection against which the outside is insulated.

The individual's new place on the inside creates the conditions for the development of associated domestic concerns. In his book The Emergence of the Interior, Charles Rice describes the crystallization of this tendency as a "new topos of subjective interiority", tracking the development of the bourgeoisie, along with a newly-developed need for domestic privacy. 


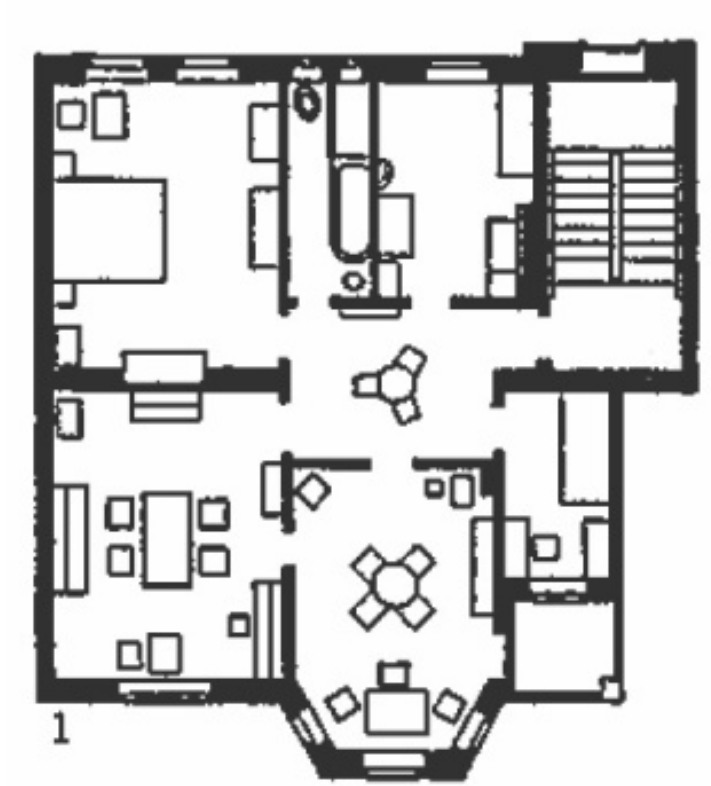

A. Bad Example

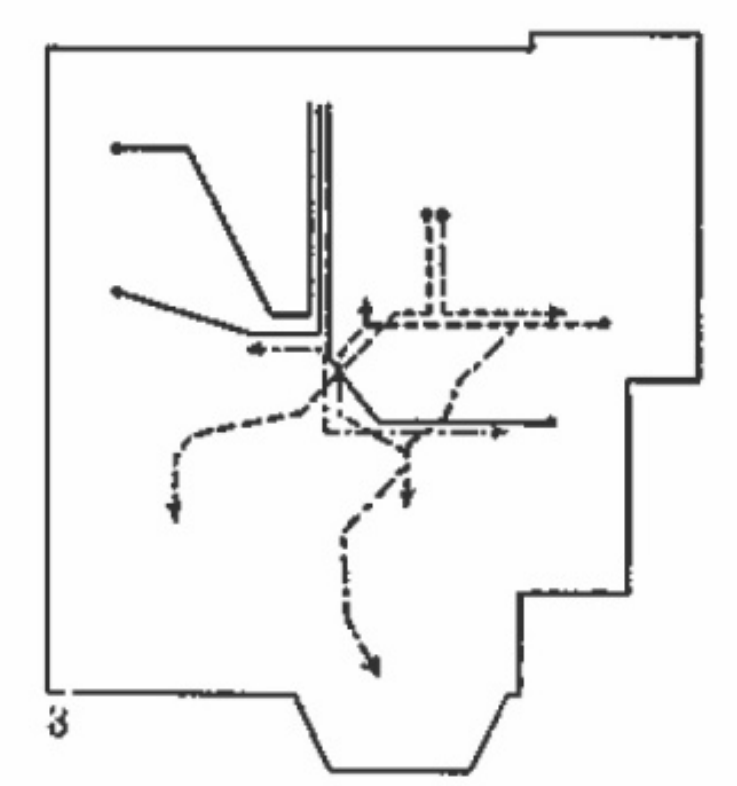

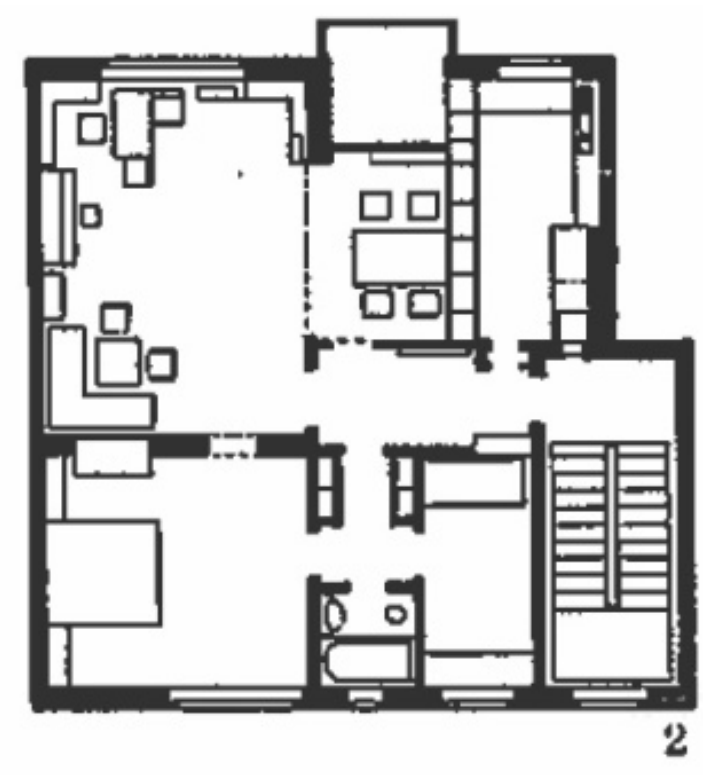

B.' Good Example

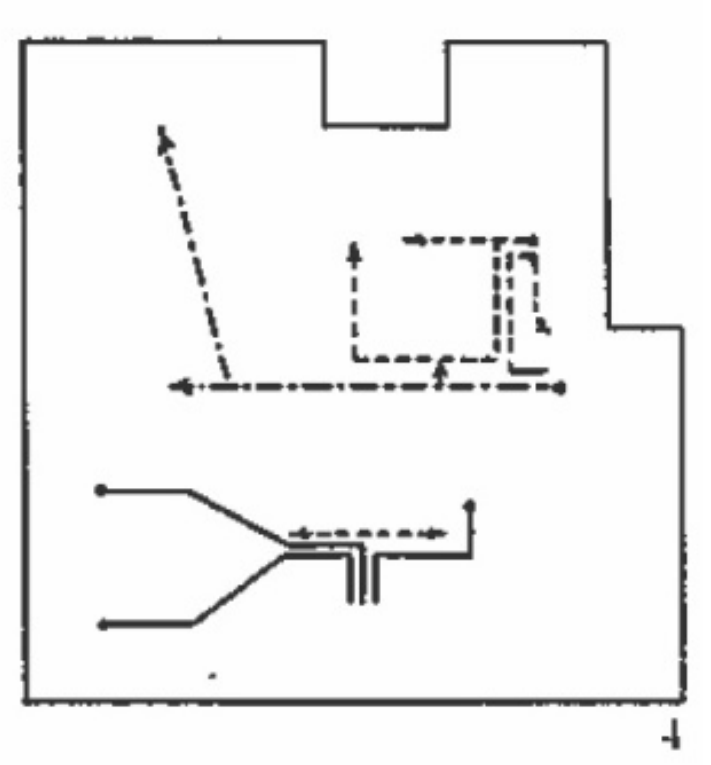

The development of the domestic interior is parallel to the introduction of the corridor, which replaced the matrix of interconnected rooms which previously supported organic interchange between inhabitants. In his essay Figures, Doors, and Passages, Robert Evans charts the development of corridor living:

This advanced anatomy made it possible to overcome the restrictions of adjacency and localization. No longer was it necessary to pass serially through the intractable occupied territory of rooms, with all the diversion, incidents and accidents that they might harbour. [...] In other words these thoroughfares were able to draw distant rooms closer, but only by disengaging those near at hand. And in this there is another glaring paradox: in facilitating communication, the corridor reduced contact. What this meant was that purposeful or necessary communication was facilitated while incidental communication was reduced, and contact, according to the lights of reason and the dictates of morality; was at best incidental and distracting, at worst corrupting and malignant. ${ }^{2}$

The theme of minimizing incidental contact saw continuation in Alexander Klein's work The Functional House for Frictionless Living (1928). Klein attempted to devise a domestic interior free of accidental encounters, where the inhabitants would behave like co-tenants who incidentally share common facilities. ${ }^{3}$ The house envisioned by Klein would seem ideal for quarantining; it would be trivial to maintain a $2 \mathrm{~m}$ distance from other members of the household in Klein's Functional House. However, this move towards a modern (and epidemiologically sound) lifestyle seems merely a stepping stone on the way towards simply living alone. What is lost when we minimize contact with other members of our household? Robert Evans mourns the social interaction that is left behind:

The cumulative effect or architecture during the last two centuries has been like that of a general lobotomy performed on society at large, obliterating vast areas of social experience. It is employed more and more Alexander Klein 

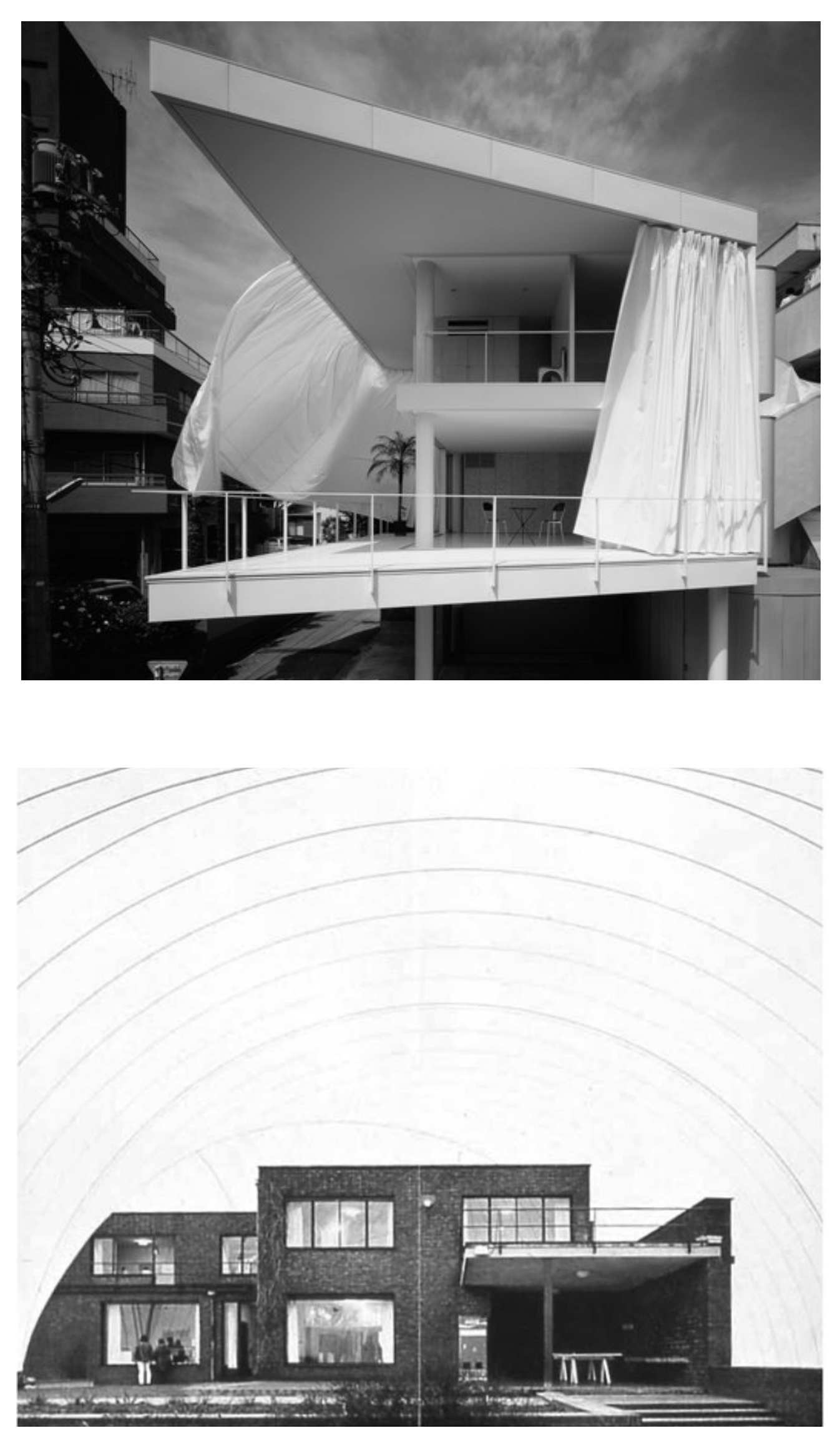

OPEN AND CLOSED:

Curtain Wall House

(Shigeru Ban)

Shigeru Ban's Curtain Wal

House from 1995 features

an adjustable liminal

space which wraps around

two sides of the house.

At the extreme exterior

of the structure, curtains

are used as needed to

shade. Sliding olazing

on the inns glazing

thermal insulation to be

deployed in winter

'Lange House Cover' by Haus-Rucker-Co

The firm HausRucker-Co designed this intervention surrounding Mies' Lange House consisting of PVC bubbles which create a microclimate in which the entirety of the building rests. as a preventive measure; an agency for peace, security and segregation which, by its very nature, limits the horizon of experience - reducing noise-transmission, differentiating movement patterns, suppressing smells, stemming vandalism, cutting down the accumulation of dirt, impeding the spread of disease, veiling embarrassment, closeting indecency and abolishing the unnecessary; incidentally reducing daily life to a private shadow-play. But on the other side of this definition, there is surely another kind of architecture that would seek to give full play to the things that have been so carefully masked by its anti-tspe; an architecture arising out of the deep fascination that draws people towards others. ${ }^{4}$

Evans is here hinting at an architecture of connection rather than division. With the emergence of the individual at home, safe from the incursions and indiscretions which characterize the factory floor or the public square, comes the insulation against exposure to - and concern over - conditions outside the bubble of home. These conditions are composed not only of social elements, but of atmospheric elements.

The phenomenon of the domestic interior is tied directly to the maintenance of interior atmospheres - atmospheres differentiated through mechanical means from conditions on the outside. That is the focus of the following section.

We have extrapolated the concept of building as shelter from the exterior environment to the concept of building as a barrier to the exterio and a container of an alternative, more benign interior climate - Kiel Moe.

In parallel to social constructions of interior space, development in the technologies of building environmental management emerged. These developments were prompted by a desire for interior thermal comfort, which was met with newly available centralized environmental control systems. The wide deployment of these systems yielded generic interiors which reinforced boundaries between inside and out. 


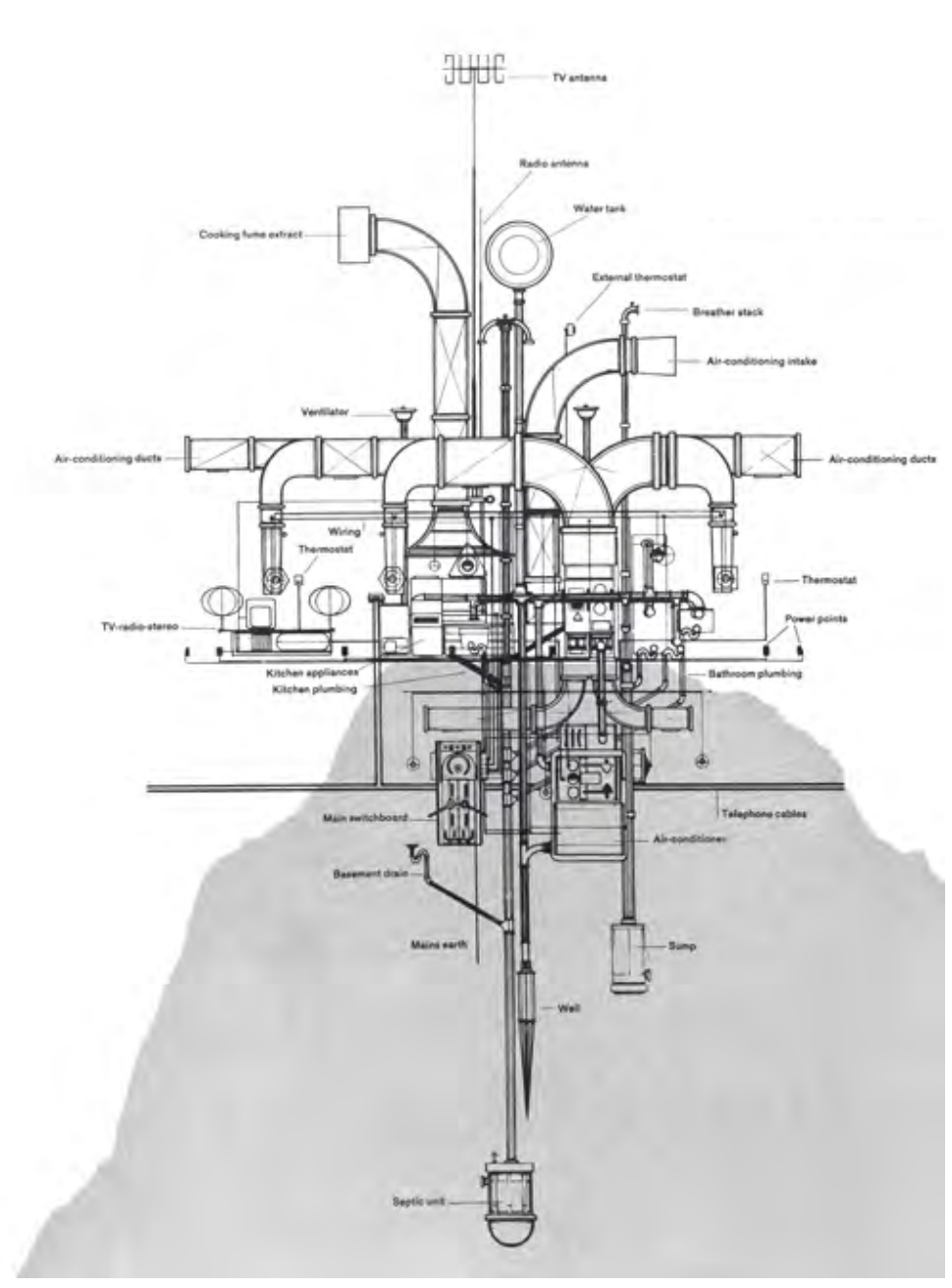

'Anatomy of a Dwelling' (Francois Dellagret)

'The junk that keeps the

image is described by the

authors. By clustering the

necessities for comfort

in one unit, the structure
Power Membrane House' (Francois Dellagret) "When your house contains such a complex of piping, flues, ducts, wires, lights, inlets, outlets, ovens, sinks, outlets, ovens, sinks, reverberators, antenn reverberators, antennae, conduits, freezers, heaters - when it contains so many services that the hardwore could stand up by itself without any assistance from the house, why have a house to hold it up?" Reyner Banham
Late-20th century environmental consciousness, empowered by developing materials engineering, laid foundations for speculation on how building envelope could be perfected to reduce the impact of human inhabitation on fragile atmospheres. Heightened awareness of building envelope performance, developed within contemporary understandings of comfort and cleanliness, yielded a uniformity of interior conditions. These are the conditions in which we find ourselves now, quarantined (explicitly or otherwise) from the outside.

The advent of effective packaged HVAC systems caused a monumental shift in focus for architectural technology. The use of centralized environmental control systems liberated the building envelope, freeing it from its role as the primary mechanism for atmospheric exclusion. Newly-manufactured consumer demands for ideal interior environments were met by ubiquitous mechanical air conditioning, which transformed the domestic sphere.

Robert Mugerauer notes that in the 1950s, the suburban

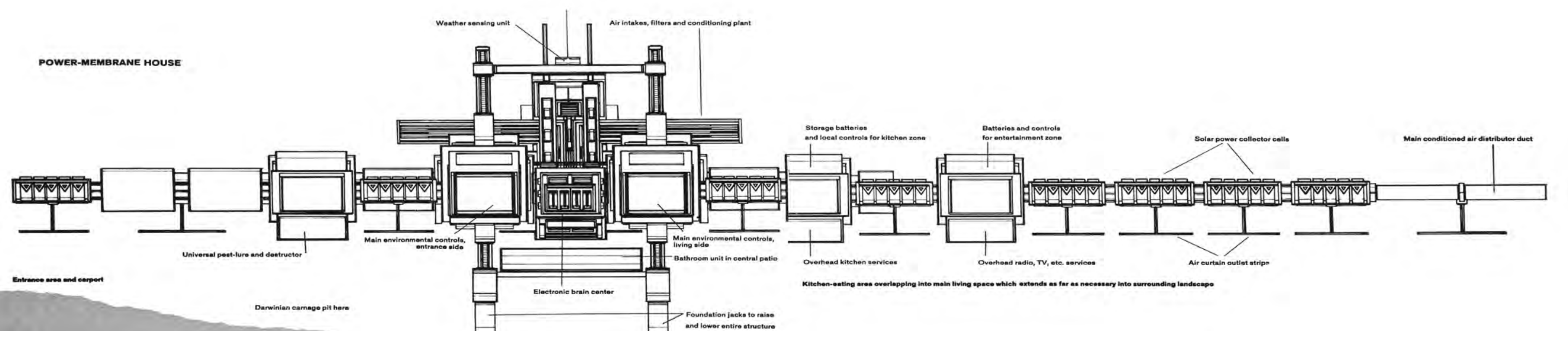




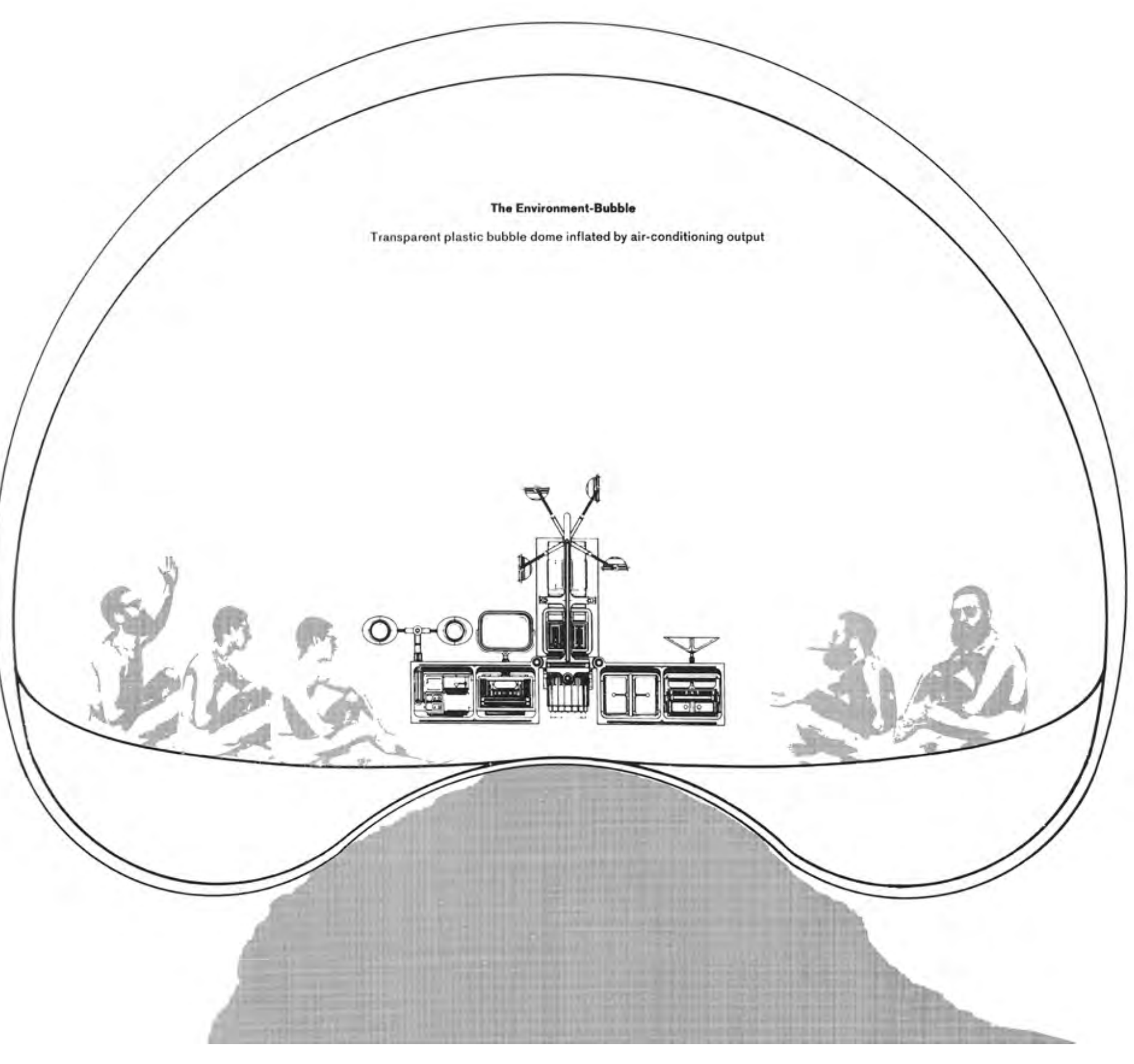
with a remote door opener, then move into the kitchen - safely home." "This total conditioning of climate opened the possibility of site-less housing; such a hyper-insulated structure could be built anywhere. As Mugerauer notes, this is the moment when "clean air" replaced "fresh air" as the climactic ideal, in which all of the systems supporting the construction of the interior environment are exposed ${ }^{7}$

Reyner Banham playfully examines the shift of environmental control measures from the building envelope to the mechanical system". In the 1965 article "The Home is Not a House", are six architectural drawings by François Dallegret which speculatively depict the architecture of the mechanical system without the building envelope elements we are accustomed to seeing - a post-monument form of dwelling: "In the open-fronted society, with its societal and personal mobility, its interchangeability of components and personnel, its gadgetry and almost universal expendability, the persistence of architecture-as-monumental-space must appear as evidence of the sentimentality of the tough." Banham opposes the heavy, permanent, monumental architecture of Europe in the American context, promoting instead a 'post-monumental' architecture of untethered lightness.

Dellagret's drawings exemplify an architecture which exerts a centripetal force over the occupants; by questioning the presence of the building itself, attention is moved to the meeting of needs through a direct feed which dispenses with ducting,

.



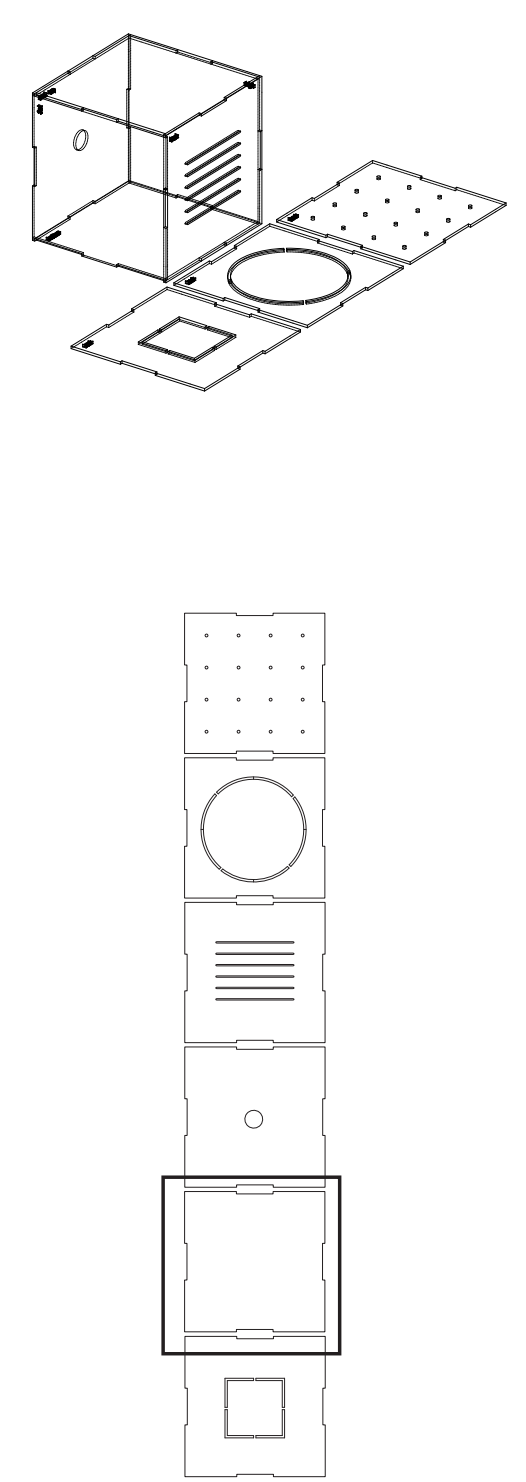

Containment Study Contact sheet 7

The construction of an interior atmosphere is suggested in this model of a totally enclosed envelope. No exchange is permitted between interior conditions and the harsh exterior.

conduits, or delivery mechanisms. This is a form of insulation via exposure, where the dweller is reduced to the role of an infant suckling from the comfort and entertainment machines newly liberated from their enclosures. The characters appearing in these drawings stand out for their uniformity (and perhaps their nudity); the messiness of domestic life is never featured.

The image entitled 'The Environment Bubble' is a sectional view of a bubble enclosing five men sitting around a bizarre contraption. The men appear to be naked, and face the center of the space where the contraption sits. The bubble sits on a rocky outcropping, as if balanced there for a moment - the potential for relocation is hinted at by the absence of anchors or foundations. The contraption is the focus of the image given emphasis through the intricacy of its depiction and the heavy tone used. It seems to take the place of a fire - a nexus of gathering and provider of comfort. The bubble itself has a double wall, and slouches over the rock on which it sits. There is an absence of any other objects inside the bubble, as if all the needs of the men are met by the apparatus and enclosure. No parts of the external world are depicted. The contraption depicted in the middle is labelled the 'Transportable Standard of Living Package', which includes entertainment, sanitation, and climate conditioning functions into a mobile, modular life support system.

Closed systems became increasingly popular in the late 1960s. Buckminster Fuller famously exhorted us to regard our little planet as a spaceship. Considering all the ingredients for our survival are to be found within the sphere of spaceship earth, Fuller's environmentalism was borne from an understanding of the earth as a closed system: "We have not been seeing our 

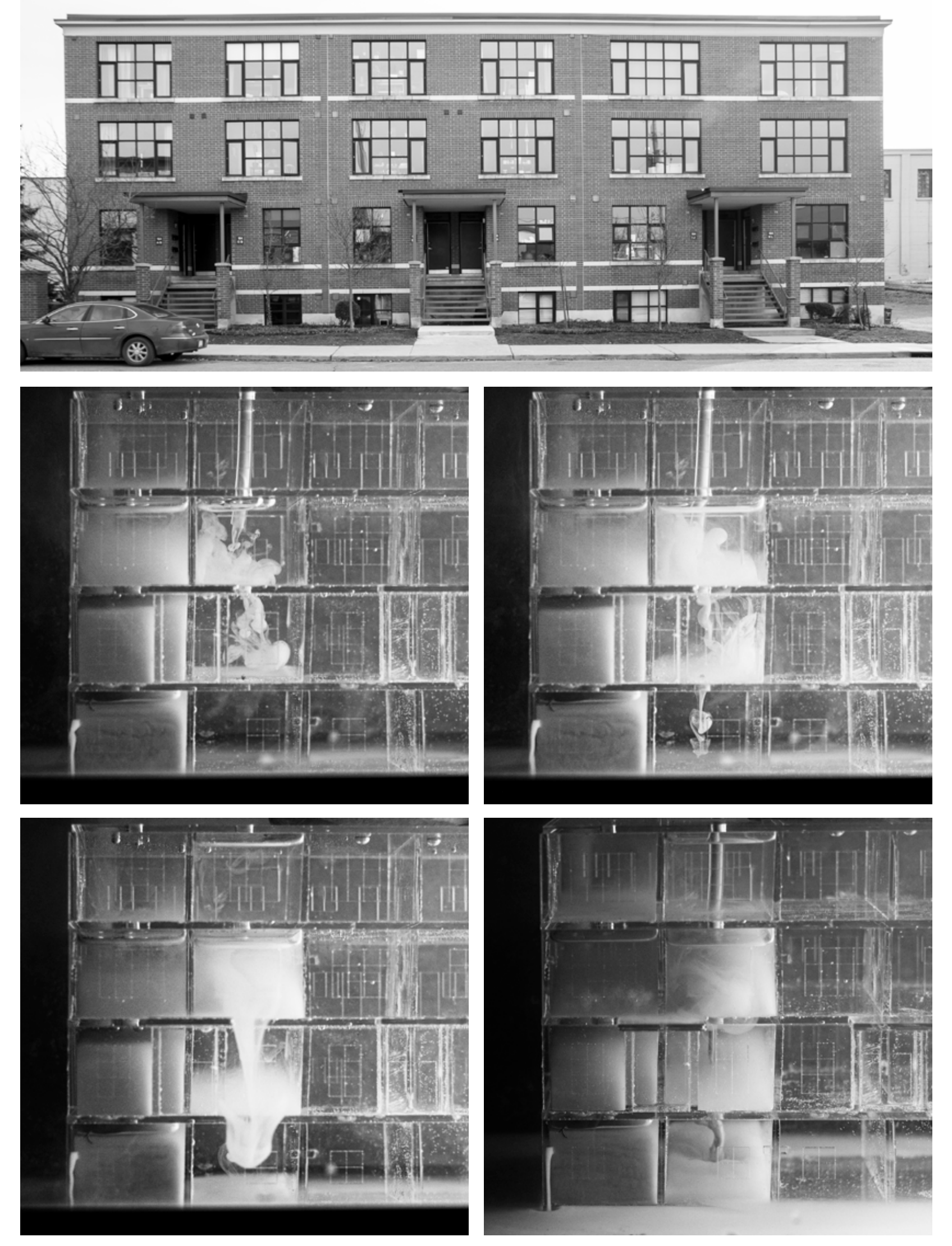

Spaceship Earth as an integrally-designed machine which to be persistently successful must be comprehended and serviced in total." ${ }^{\prime 10}$ Landscape designer Ian McHarg suggested architects "can use the astronaut as our instructor." 11 The decline of space exploration accompanied a shift in focus to architecture, which inspired projects predicated on the maintenance of tight barriers between the region of concern and everything outside.

Sean Lally observes that this tendency is akin to the gas mask - an idea reminiscent of Sloterdijk's assertion that gas warfare in the first World War caused a sudden violent reckoning with air as a charged medium. "The gas mask that protected the eyes and nose from a poisoned environment became an appropriate analogy for homes and public buildings that would seal themselves off so as to heat and cool their interiors and filter the variables - sun, winds, and odor - of the outside world." ${ }^{12}$

Lydia Kallipoliti's The Architecture of Closed Worlds depicts 37 closed systems 'that put forth an unexplored genealogy of closed resource regeneration systems.' For each project, Kallipoliti documents failures in the projects' ability to keep the outside out. From space travel to sealed biospheres, a common thread documented in these projects is the impossibility of survival in conditions of environmental isolation. The 1972 Ecological House was designed as a living laboratory of closed cycles and radical Contact sheet 10.

In this case study a contemporary condominium project was used to analyze the flow of conditioned air through dwelling units. The ventilation of the source building was represented with apertures in the model. recycling. The builder, Graham Caine, was determined to recycle human feces in an effort to produce a zero-waste dwelling. Caine's structure was ardently anti-architectural; by focusing on the systems inside, the form of the 'building' simply served as a container for the systems inside. Absent was any meaningful engagement with conditions and systems outside the bubble, which yielded not only an unbearable interior atmosphere full 


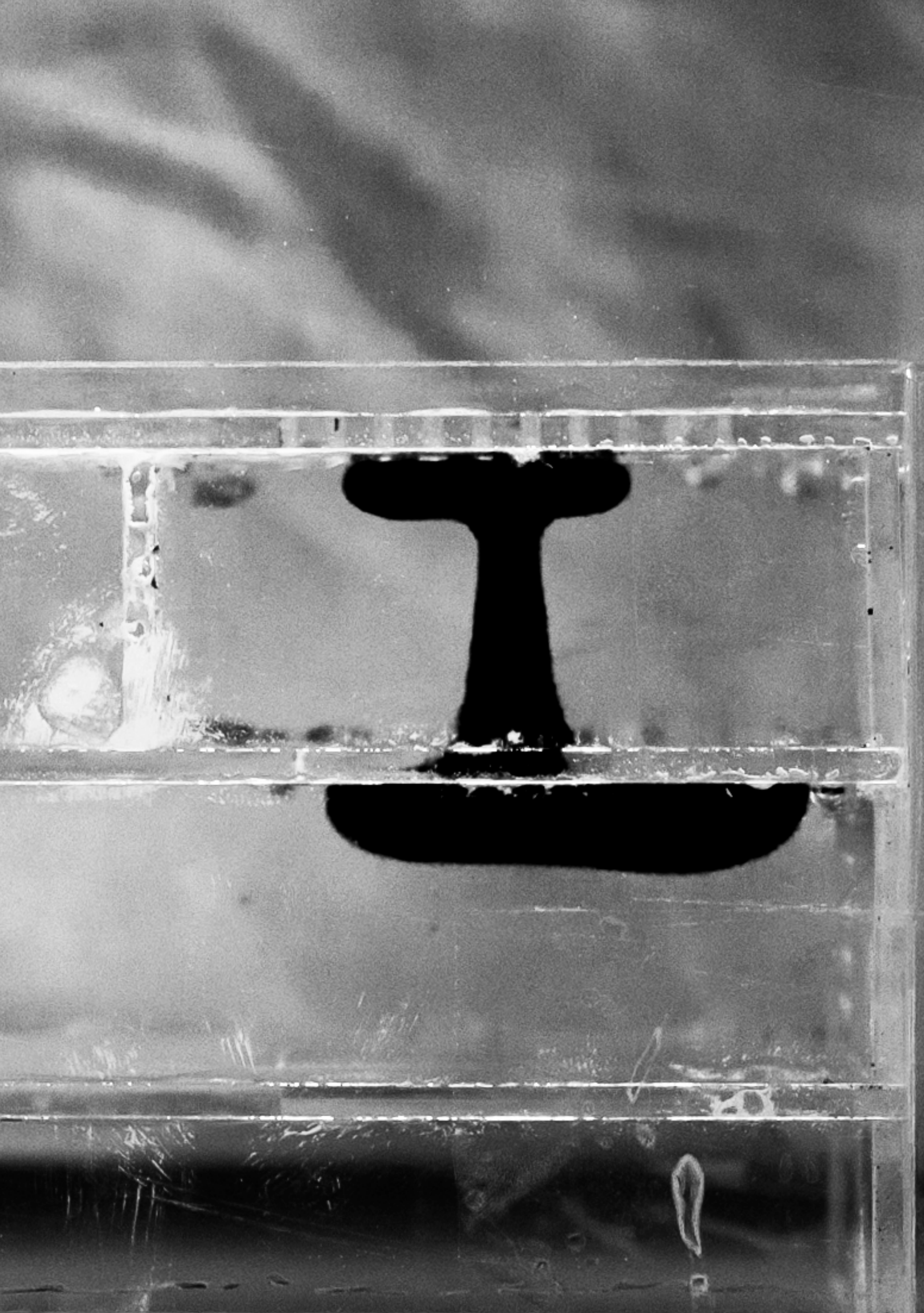

of effluent and the by-products of decomposition, but a blank, formless presence on the site.

The approaches taken by Banham and Caine challenge the form of the envelope using a transformed material presence, but amplify and reinforce its performance as a seal against the outside. These experiments call into question the remaining tasks carried by the building skin - including the division of those inside from those outside. With the questioning of the role of that skin comes an opportunity for calibrating the performance of those walls. The following chapter investigates the socialspatial exclusion that accompanies contemporary atmospheric exclusion, and hints at possible reconfiguration of domestic boundaries. 


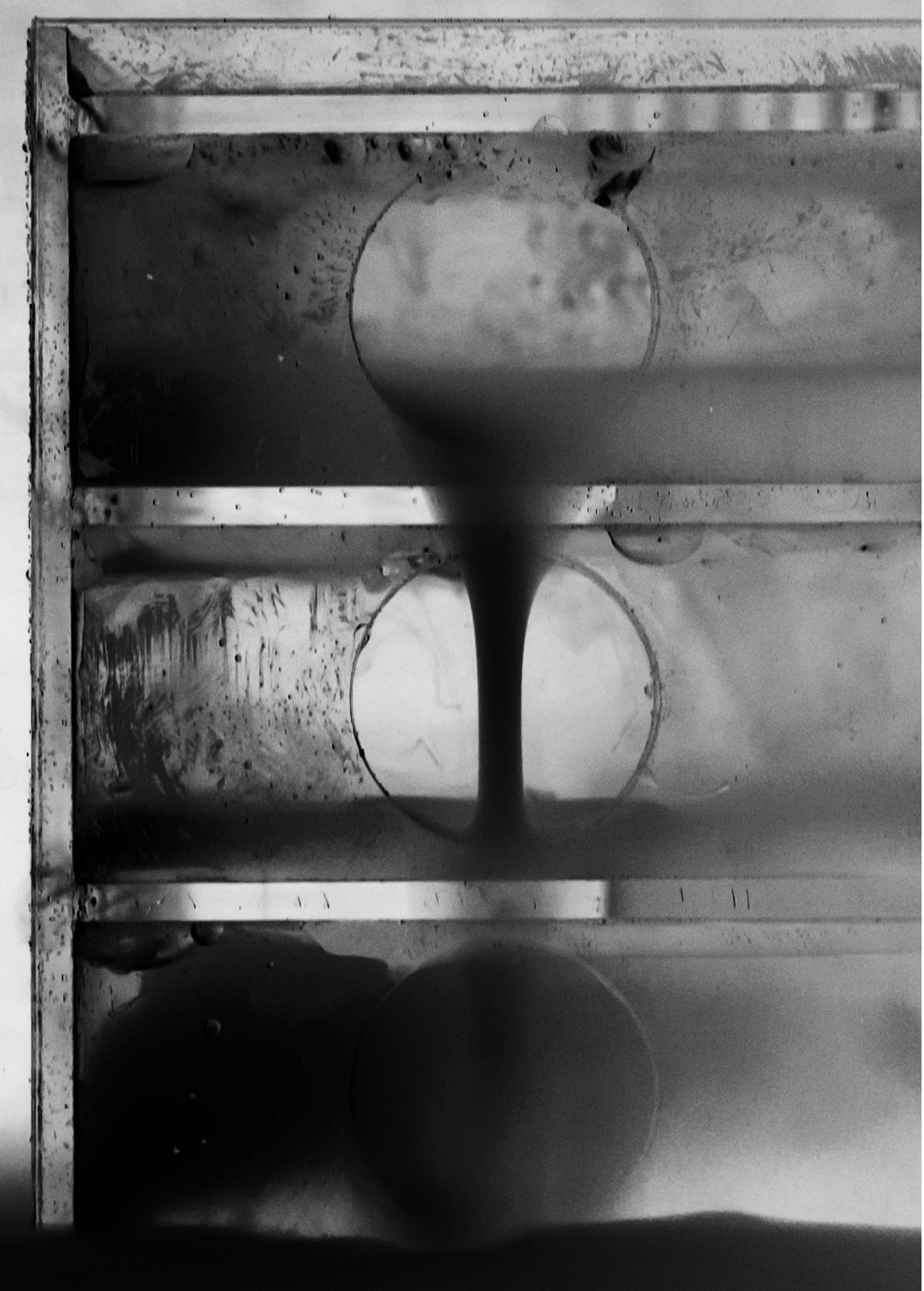

Inter-floor flow testing
$(2 / 2)$. Contact sheet 9

A circular aperture permits 


\section{Chapter 2: Collective Isolation}

"Houses are Built Immune Systems" - Peter Sloterdijk Contact sheet 8

In this study a

contaminant (sand)

was introduced into the

'atmosphere' to illustrate

the maintenance of

a 'sphere of concern'

through the rejection

of contaminants. If the

extents of our care are

defined as existing only in

the bubble, atmospheres

must be strictly free of

foreign entities.
To engage conditions of domestic atmospheric isolation requires an understanding of socio-spatial topology. Foams by Peter Sloterdijk - the third and final installment of his Spheres trilogy - serves as a point of departure for this effort. In particular, Sloterdijk identifies the modern apartment (which he refers to as the 'egosphere') as a material and semiotic expression of defensive isolation. The apartment unit is a bubble in the 'foam' of modern existence - a cell in the agglomeration of isolated spaces which define contemporary social life. Sloterdijk's work is used as an entry point for investigating isolation and openness through the phenomena of environmental and social mediation.

The boundaries that define spaces of interiority are fundamental building blocks of inclusion and exclusion. By dividing spaces into conditioned/ unconditioned, we define groups of dwellers which reside in comfort together - the household group. The creation and maintenance of these groups and boundaries is a deeply established cultural practice which is so familiar as to be invisible.

Where are we when we are in the world? This is the question posed by Sloterdijk in his spatio-metaphysical magnum opus trilogy Spheres (Sphären). In a response to Heidegger's solitary conception of being-there (dasein), Sloterdijk formulates an affective dyadic foundation for social existence, bounded by limits called 'spheres': “the being-in-spheres constitutes 


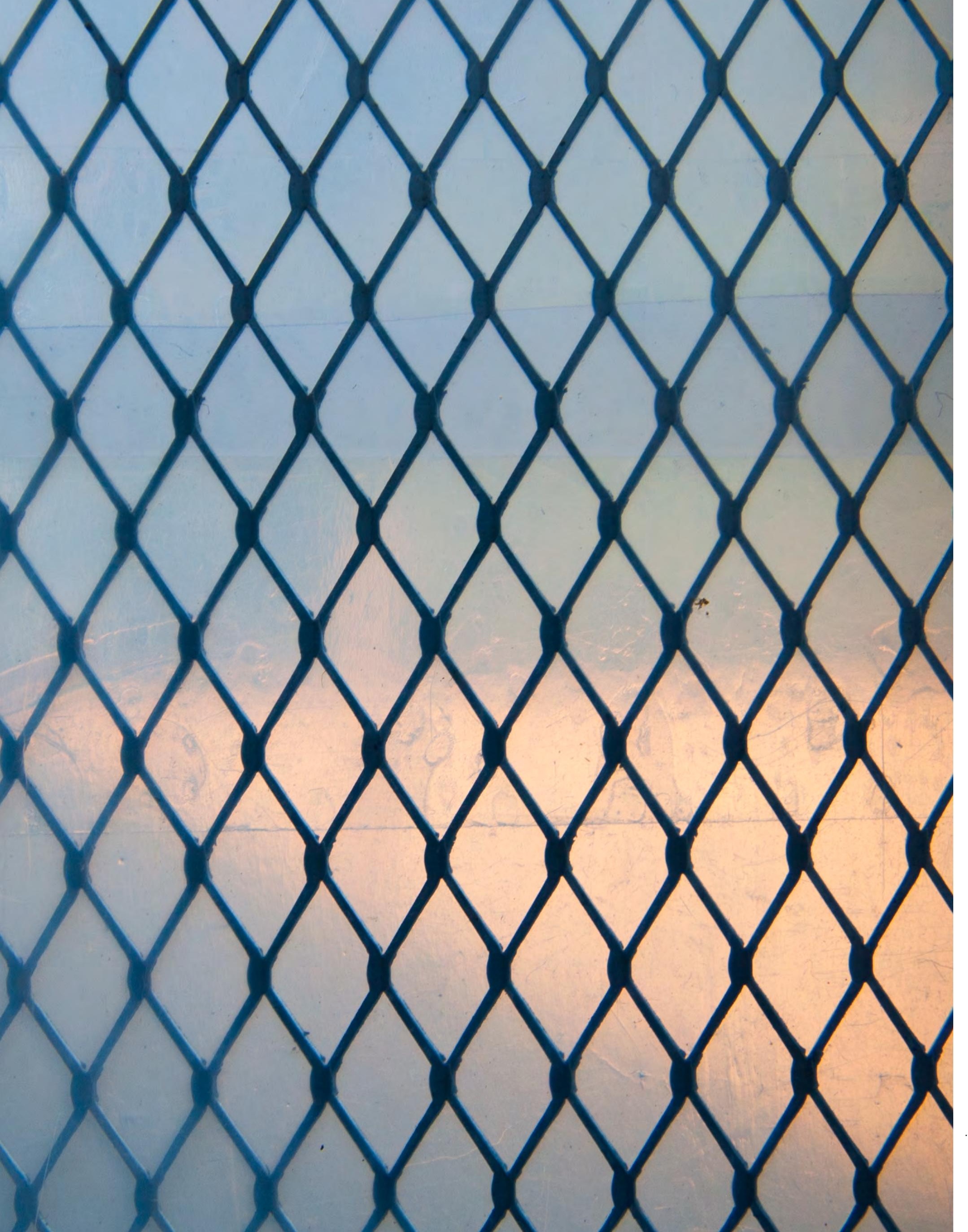

the basic condition of humans"13. Spheres are "dyadic spaces of resonance" 14 in which a small group defines a safe space through the act of exclusion. This exclusion is both material and symbolic. The portion of air around which a dwelling is built defines the atmospheric sphere of the dwelling, but also the social space of the household. As described by Christian Borch: "Spheres provide the people who live in them with an essential communion (they breathe the same air, share the same ideas, etc.), but they also supply them with a protective membrane that produces an immunity, however fragile, to the extra-spherical world." 15 According to Sloterdijk, the establishment of barriers around small groups of individuals is an expression of yearning for the re-emplacement of the walls of the womb. "Each bubble is a 'world', a place of sense, an intimate room that resonates or oscillates with its own interior life."16

According to Sloterdijk, human relations are irreducible past the level of the sphere, so basic as to be invisible. In the words of Huib Ernste, "Spheres are affective orderings of living together." ${ }^{17}$ The material expression of the inside is clearly mirrored in the construction of divided dwelling units. But what to make of our larger relational position regarding phenomena outside our subdivided spatial residence? According to Sloterdijk, bubbles of concern are not only irreducible, they are present in our relation to the greater world: "The outside is at best something we create from the inside."18

A key element of spherology is its dyadic nature; we View study with layers. Contact sheet 1

A defensive position towards the exterior impairs our perception of conditions outside the bubble. are not solitary creatures, but create shared meaning through collective understanding. As summarized by Huibe, "So it is not through our individual experience of the world, but through a joint clearing, conceding, and giving space (Einräumen), a joint 
creation of a topological network of relations, that we create our sphere" 19

As described in the third volume of the Spheres trilogy, Sloterdijk describes the form of sphere clusters - termed 'foams', a spatial description of societal groupings. "Foam has several chambers or cells that are separated from one another by thin walls, implying that the various cells are subject to a state of co-fragility; foam is generally disordered and has no centre; and it is characterized by spontaneous generation." ${ }^{20}$

Sloterdijk positions the modern apartment as an explication of foaminess due to its property of dense coisolation ${ }^{21}$ : "an aggregate of micro-spheres (couples, households, companies, associations) of different formats that are adjacent to one another like individual bubbles in a mound of foam and are structured one layer over/under the other, without really being accessible to or separable from one another."22

This concept speaks to the alienation of quarantine in highrise dwelling. As Mugerauer describes: "The image proposed as a paradigm for today's housing is that of a 'kind of container capsule' for care of self in a comfortable, media-filled surrounding, with only minimal relationships with neighbors in a building that is planned as an aggregate - this within the city that as a macro-foam is a meta-collector of co-existences, of neighborly differences. In such a habitat people "co-exist in connected isolation," each with their own self-stressing care practices." 23

By considering the nature of symbolic boundaries, we are offered hints about how to re-calibrate material boundaries. If symbolic boundaries are ever-shifting, ephemeral, and fluid, why can't those same qualities be expressed in architecture? In the context of atmospheric isolation imposed by quarantine, is there a way to redraw the lines between dwelling units in a way that captures the fluidity of social boundaries?
Explication: "the revealing incorporation of latencies or background

circumstances into

manifest operations 


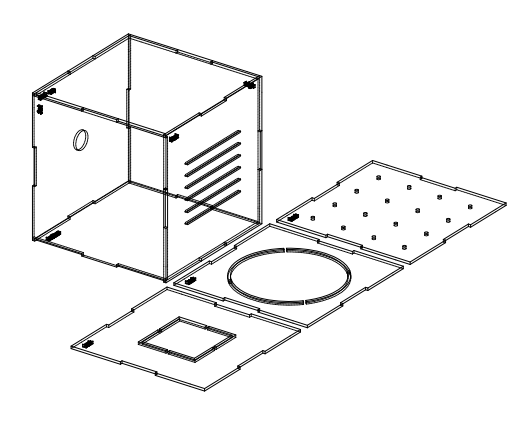

Chapter 3: Filtration

"The fabric of a building itself is no longer merely a passive container of space for ignored bodies, but an active agent in the performances of buildings and bodies." - Kiel Moe ${ }^{24}$

Can we construct a material boundary that is sensitive

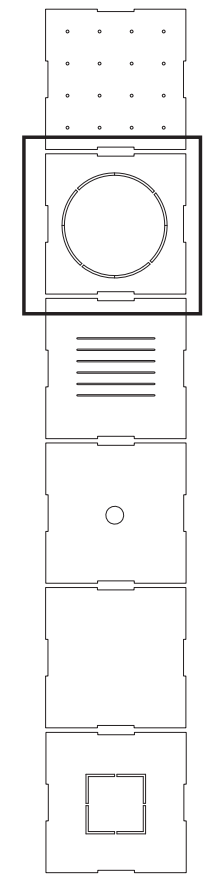
to the needs of inhabitants while also maintaining selective permeability for elements of environmental and social alterity? This task requires a teasing-apart of the qualities of those elements, along with a renunciation of binary open/closed systems.

As a counterpoint to closed environmental systems with uniform interior atmospheres, architectural theory has in the last few decades considered more nuanced approaches to interior environmental control, as well as the tectonics that enable it. Present in many of these cases is a return to the acceptance of exterior conditions in the interior, a phenomenon which was the norm prior to the dominance of packaged building environmental control systems.

Dean Hawkes defines a selective strategy of environmental design in contrast to an exclusive strategy; 'selectivity' here referring to a localized, personalized control of interior comfort informed by individual preference and body type, taking into
Filtration study. Contact sheet 6

Uniform conditions on on side of a barrier can yield dynamic and unpredictable conditions on the other side. consideration elements of passive heating and cooling where possible. By decentralizing control mechanisms, conditioned air is provided to occupied areas only where needed. ${ }^{25} \mathrm{~A}$ key element of this approach is the acceptance of exterior atmospheres in the interior. In this way, the building envelope moves towards 



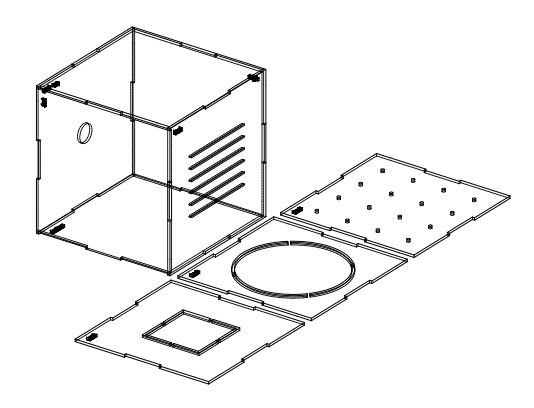

$<$

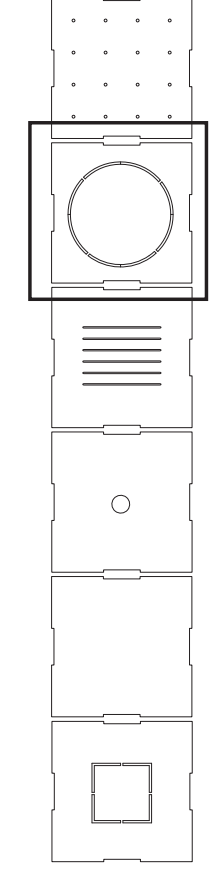

Enclosure approximation experiment. Contact Sheet 5. A circular aperture creates a fluid flow that recalls a shifting, ephemeral 'enclosure' which defines space while retaining fluidity. afternoon but buffeted by the wind. There is also the inside, with its shelter from the rain and wind and sun, and the roof, raised above ground level, more exposed to wind and sun. A building increases the available range of thermal zones so that people can select the microclimate most suited to their thermal needs." 28

Heschong observes that along with uniform interior conditions comes the loss of a powerful medium of human perception, as thermal gradients are nullified: "When thermal comfort is a constant condition, constant in both space and time, it becomes so abstract that it loses potential to focus affection." ${ }^{29}$ Unlike a beloved quilt which is identifiable as the source of comfort, batts of insulation are anonymized behind gypsum. Heschong notes that an element of variability helps to anchor our attention on certain comfort technologies (shutters, for instance).$^{30}$ One result of this phenomenon is the diffusion of activities once focused within the home due to pockets of thermal difference.

In The Air From Other Planets, the speculative architect Sean Lally envisions an architecture of fields and gradients which provides an alternative to abrupt barriers and static forms: “.. intensified pockets of energy will also become new methods for organizing the activities and events of our domestic and public lives, informing social interactions in a manner not seen in the effects exerted today by surface architecture" 31 (emphasis mine). Later Lally imagines an architecture of pure energy: "It follows that if energy could be controlled and deployed as physical boundaries that define and organize spaces the human body can detect and recognize, wouldn't that be architecture?"32

Such an approach infers the renunciation of solid architectural form as the sole performative element of the built 


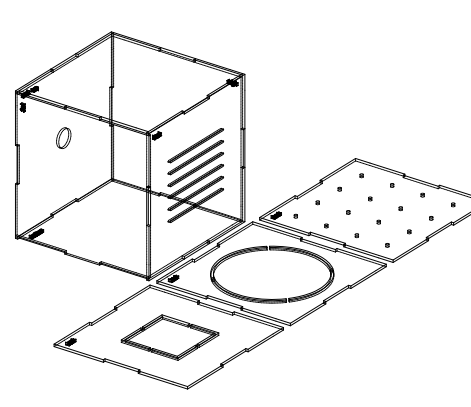

environment. Alongside this questioning of form comes an interrogation of the role of thermal comfort mechanisms in the maintenance of inhabitable interiors. By acknowledging the power of thermal conditions in shaping human experience, and by re-centering the occupant as an active participant in a field of rich sensory feedback mechanisms, thermal experience moves beyond a neutral, 'optimized' interior.

Lally identifies the limits of mediation as an approach; he proposes an architecture of amplification: "strengthening and augmenting the characteristics and properties of the particles and waves that both the surrounding environment and architecture share." ${ }^{\prime 3}$ However, Lally's visions for an architecture of energy comes up against intractable issues of material expression; while notions of an architecture of pure energy are intriguing, it remains to be seen how flows and fields can fill the manifold roles of building materials. Elemental architectural forms as basic as the multi-story building are difficult to construct when all we have in our toolbox is heat and light. Indeed, Lally's own examples of this sublimated architecture feature all-too-familiar material and tectonic expressions which support subsystems sporadically activated and supported by his energy architecture. Despite these reservations, there remains a valuable lesson in Lally's embrace of vaporized construction.

These investigations clear space for a revised conception of interior inhabitation - a conception embracing variability, gradients, and pockets of thermal difference which reframe the occupant as an active node in a field of dynamic flows. 


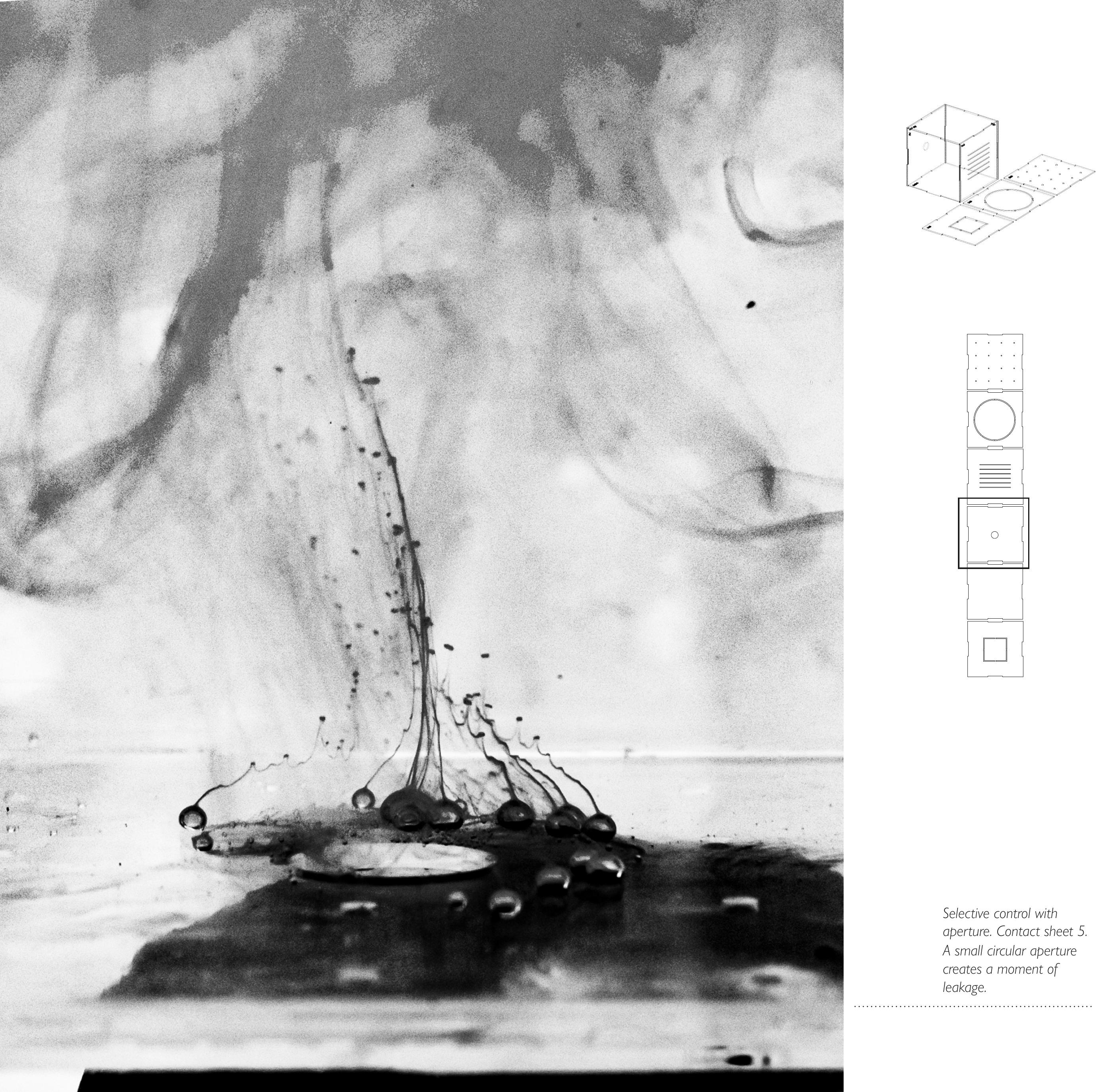




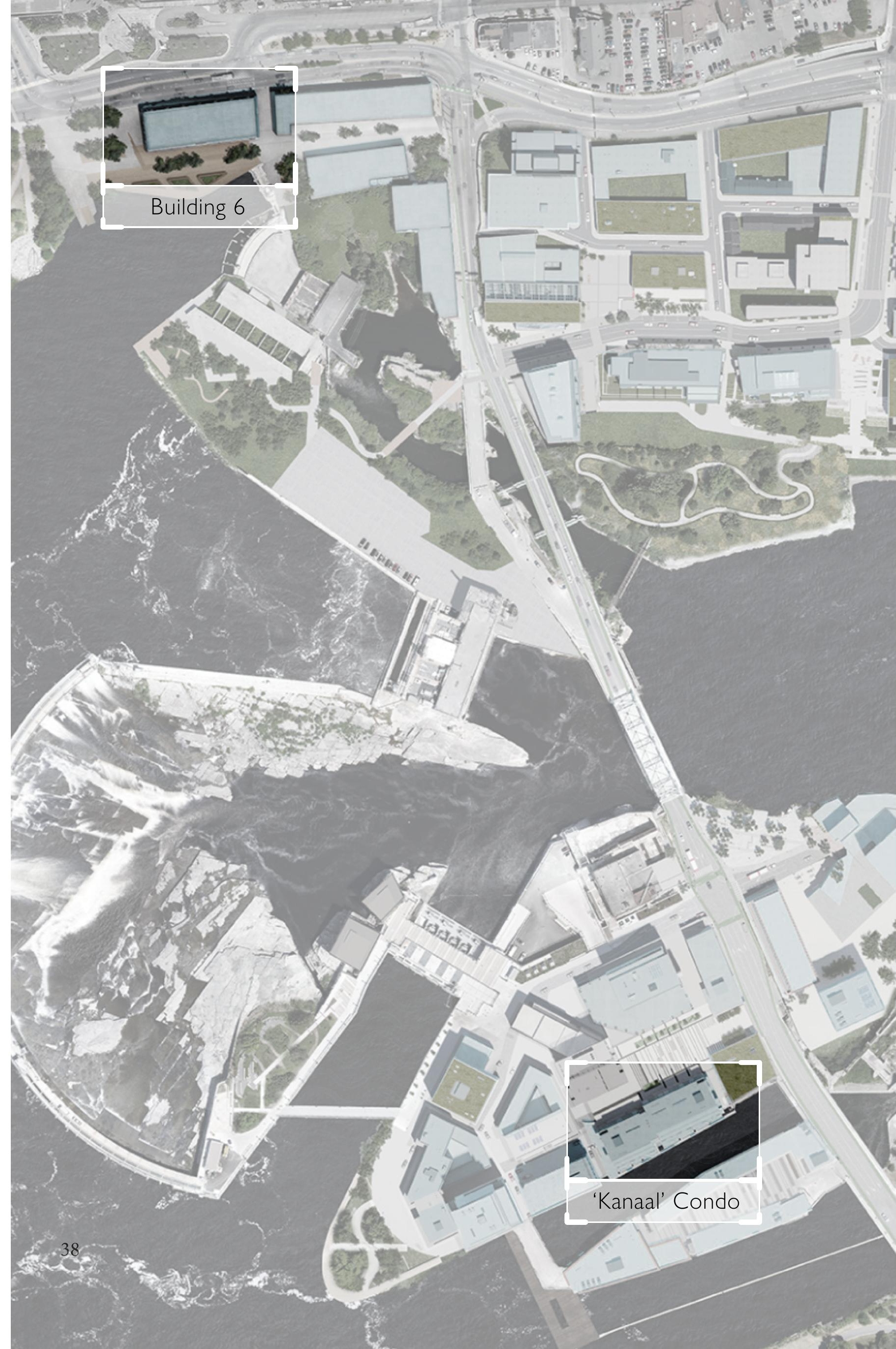

At the time of writing, the planet is thrust into a pandemic. An airborn virus has radically reoriented reciprocities between social exchange and environmental processes. Mandates for managing the spread of the virus involve face masks, limiting collective time indoors, two week quarantine periods following international travel, two meter distancing in public spaces, and reduced or eliminated contact with close family and friends. In response, new social patterns have emerged, largely relegating social interaction to exterior spaces regardless of weather, inscribing the public domain into two meter diameter personal 'bubbles'.

Pre-existing tendencies toward isolation are deepened and exacerbated by the current crisis, and there exists an unprecedented concern over the qualities of interior air. I contend that lockdowns and quarantines are no more than a continuation (or amplification) of a tendency towards hyperisolated interior spaces. The sealed interiors of quarantine space are ripe for reimagining, with a consideration for contact with elements outside the bubble.

With heightened awareness of pathogenic transmission, air is understood as a potential threat. A posture of defence develops against air of unknown origin, which enforces conditions of quarantine on inhabitants whether or not this condition is externally imposed.

Zibi site plan showing site of intervention ('Building $\left.6^{\prime}\right)$ and site of critique ('Kanaal Condo').
To focus these investigations into enclosure and mediation, an intervention is proposed here which offers an 


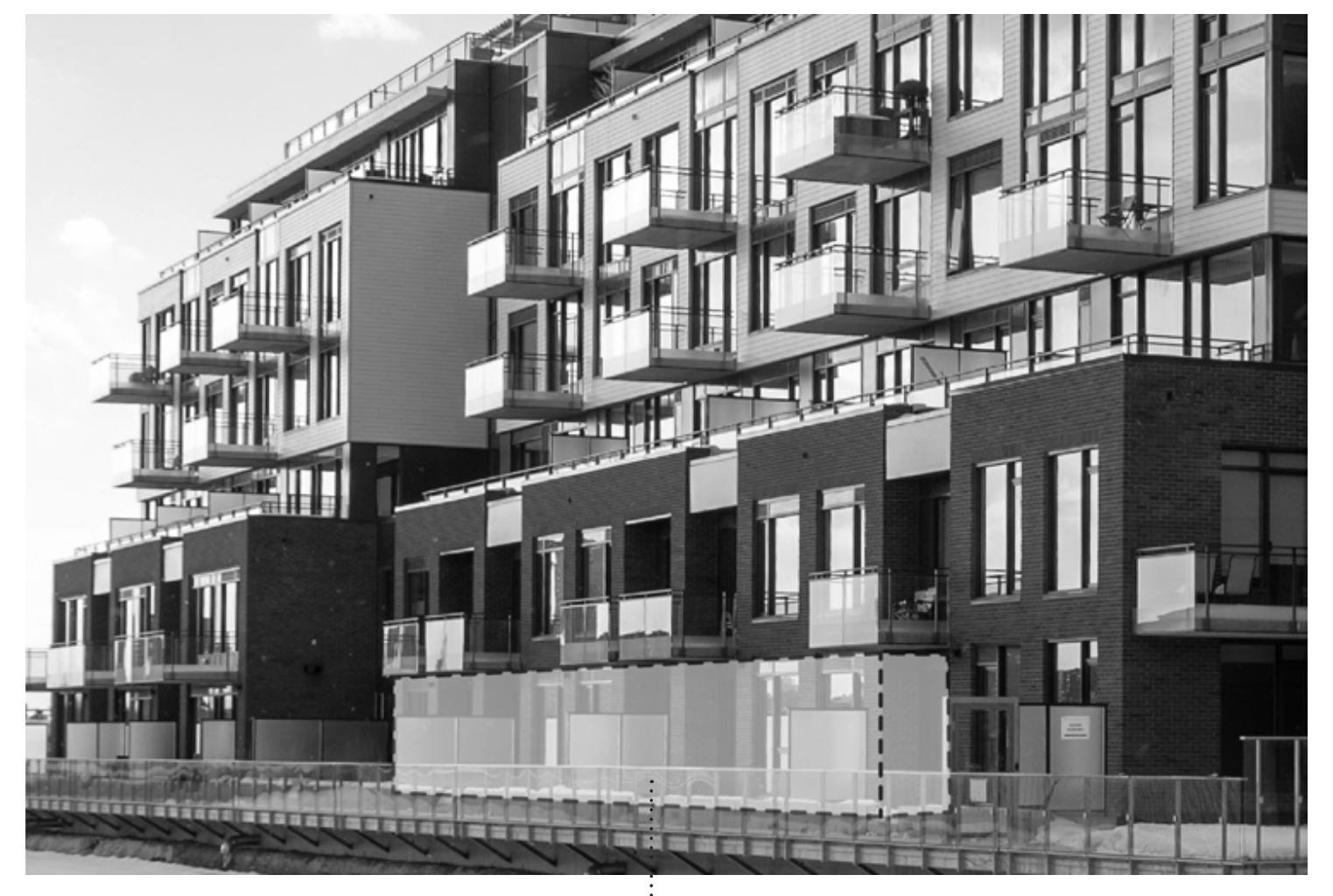

alternative vision of the interior - one which offers moments of exchange to counter the phenomenon of the hermetic.

The Zibi development is a mixed-use development under construction on a site which spans the Ottawa River in Ottawa/ Gatineau, Canada. Formerly the site of a paper mill, the project involves the construction of several new residential towers, and the restoration of several stone warehouses for light retail use.

In the Zibi development, high density housing projects exhibit typological apartment-condominium traits common in the greater National Capital region and elsewhere: projects feature stacked units with common areas shrunk and packaged as 'amenities', single-use planning prevails save for the occasional café included in marketing materials, and projects are disconnected from the existing urban fabric (think: cul-desacs instead of through streets). While residents are spatially proximate to one another, paths of travel lead directly from entrance to spaces of privacy, hermetically sealed from any intrusion. There exist clearly enforced binary conditions between inside and outside, secure and exposed.

Environmental control measures further enforce these binaries. By thoroughly insulating interior spaces, neutralizing interior atmospheres to a narrow predefined band of comfort, and delivering meticulously filtered air, these buildings perform the duties of a gas mask. As the qualities of 'inside' air are perfected, 'outside' air becomes alien.

In Sloterdijk's human topology, foam boundaries are defined as ever-shifting, fluid, and overlapping. Sloterdijk asserts that a successful housing project behaves as a 'psycho-social 


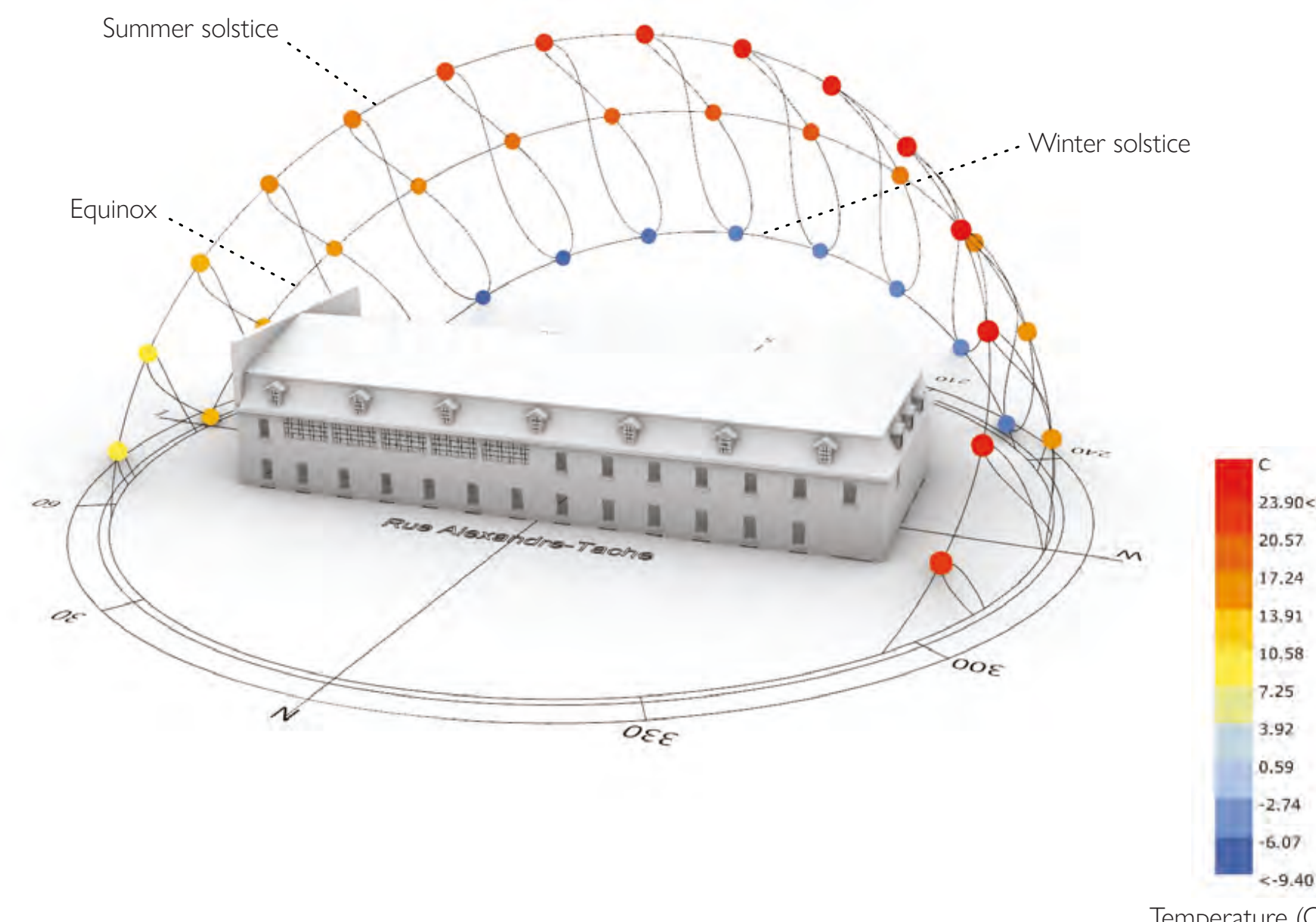

Temperature (C)

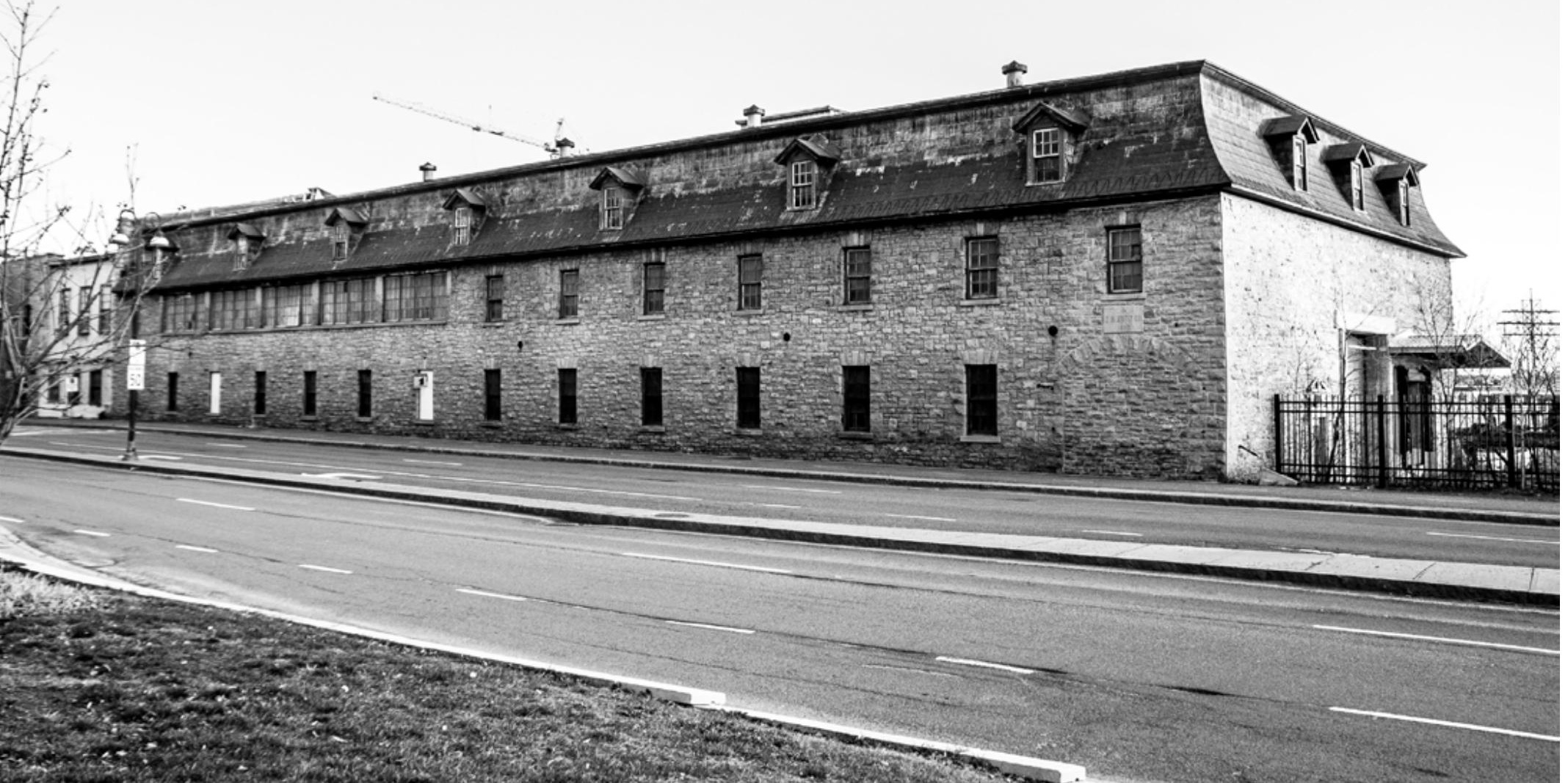

selectively invite elements from its environment. Certainly this is a foreign concept in the projects described above.

The building selected as the site of intervention is referred to as the Domtar Building 6. It is a stone and heavy timber structure in a neglected corner of the Zibi complex which was primarily used as a warehouse for the Domtar paper factory.

The project is conceived as a quarantine hotel. It is designed to counteract the phenomenon of co-isolation that occurs during the process of quarantine. The project rethinks the performance of the boundaries between spaces of the interior and exterior, and between adjacent interiors. By separating the functions of atmospheric and social mediation, the performance of those boundaries can be calibrated to selectively permit elements of alterity. By redrawing the lines around boundaries of concern, the process of explication described by Sloterdijk is furthered and refined.

The Quarantine Hotel is designed to counteract the phenomenon of co-isolation. By disrupting the barriers which prevent the knowing of conditions outside the bubble, while actively shaping airflow to prevent disease transmission, it offers an alternative vision of high-density dwelling in the coronacene. ${ }^{34}$

The core group of inhabitants in the Hotel are those who rely on others for care, but whose symptoms (if present) are considered too mild for hospitalization: individuals and families quarantined (due to recent travel or exposure) who cannot meet their own daily needs are housed alongside those who are able to provide care. As the range of requirements shift, guests are able to control their level of exposure to elements and inhabitants outside. In this way, the ever-shifting topology of Sloterdijk's 
The condition of quarantine is characterized by restrictions to movement, limits to contact with others, and heightened concerns around airflow due to the risk of pathogenic transmission. These restrictions are reframed as opportunities to rethink conventionally understood approaches to environmental and social mediation using a series of novel building components. These components are: the Filter Vent, the Thermal Attractor Pad, the Chimney Lung, and the Party! Wall. Their roles in constructing atmospheres and social exchanges are outlined in the following pages. Collectively, they are assembled into a building described both through building axonometrics, which enable visualisation of the building as a total assembly of components. A series of final model studies makes evident the nature of some of the designed quarantine atmospheres. 

(1) Chimney Lungs
(2) Filter Vents
(3) Party! Walls
(4) Thermal Attractor Pads

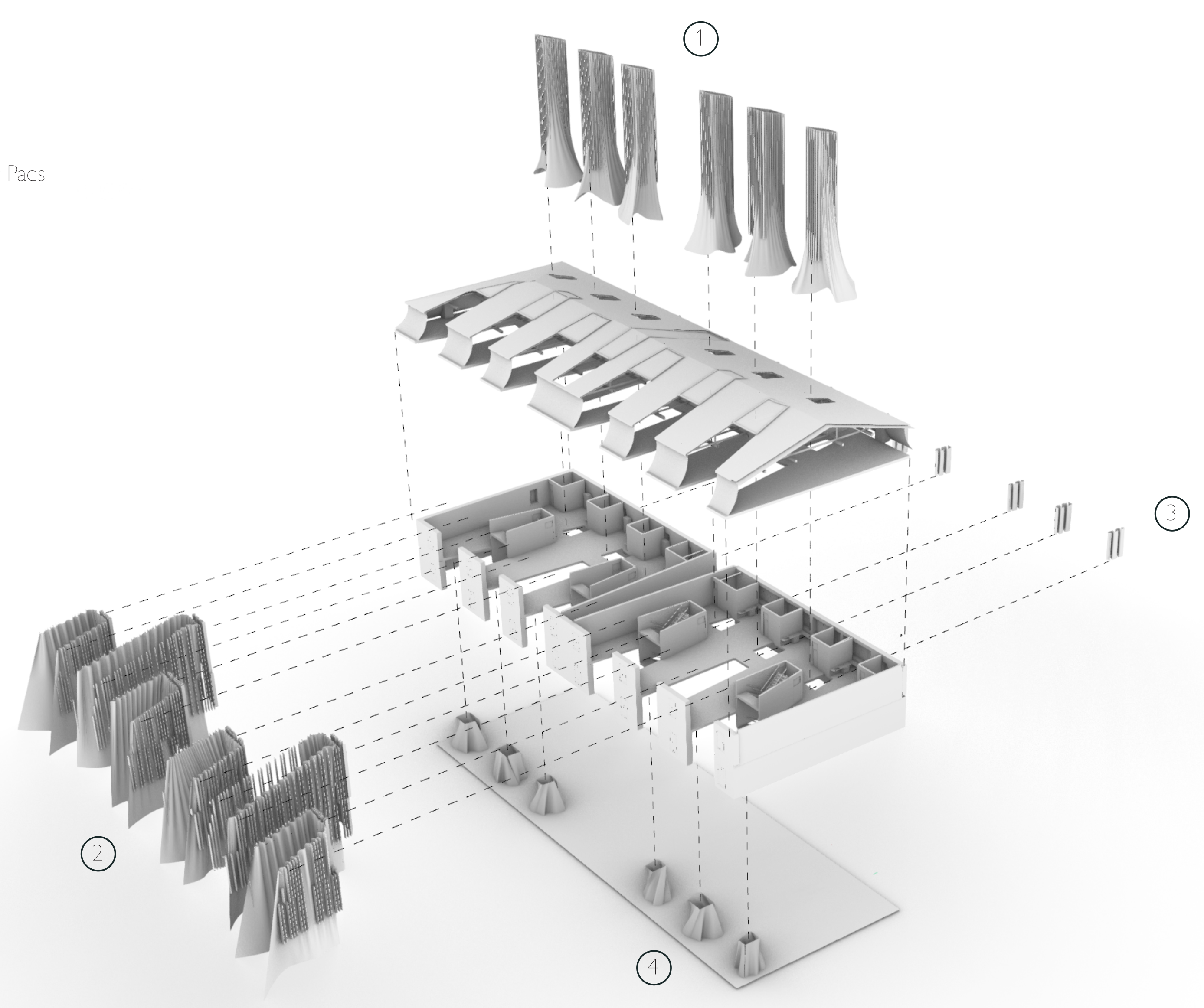




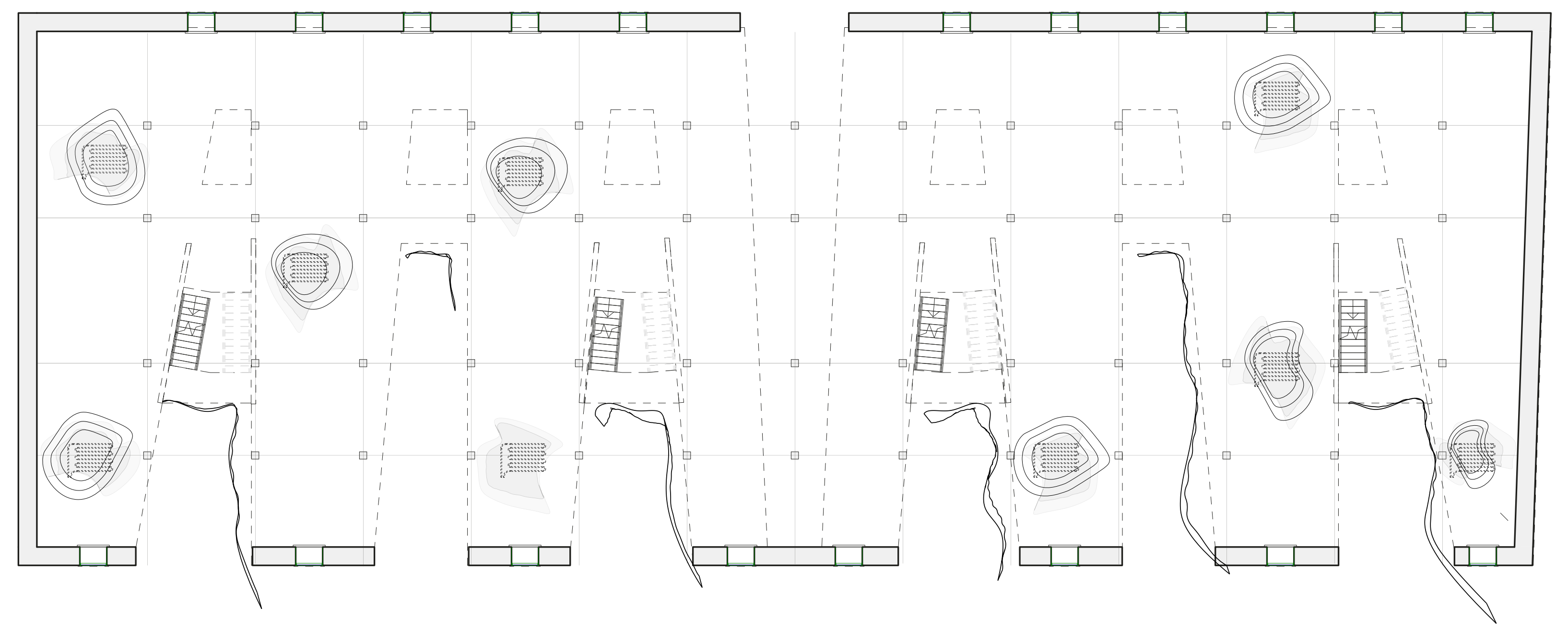




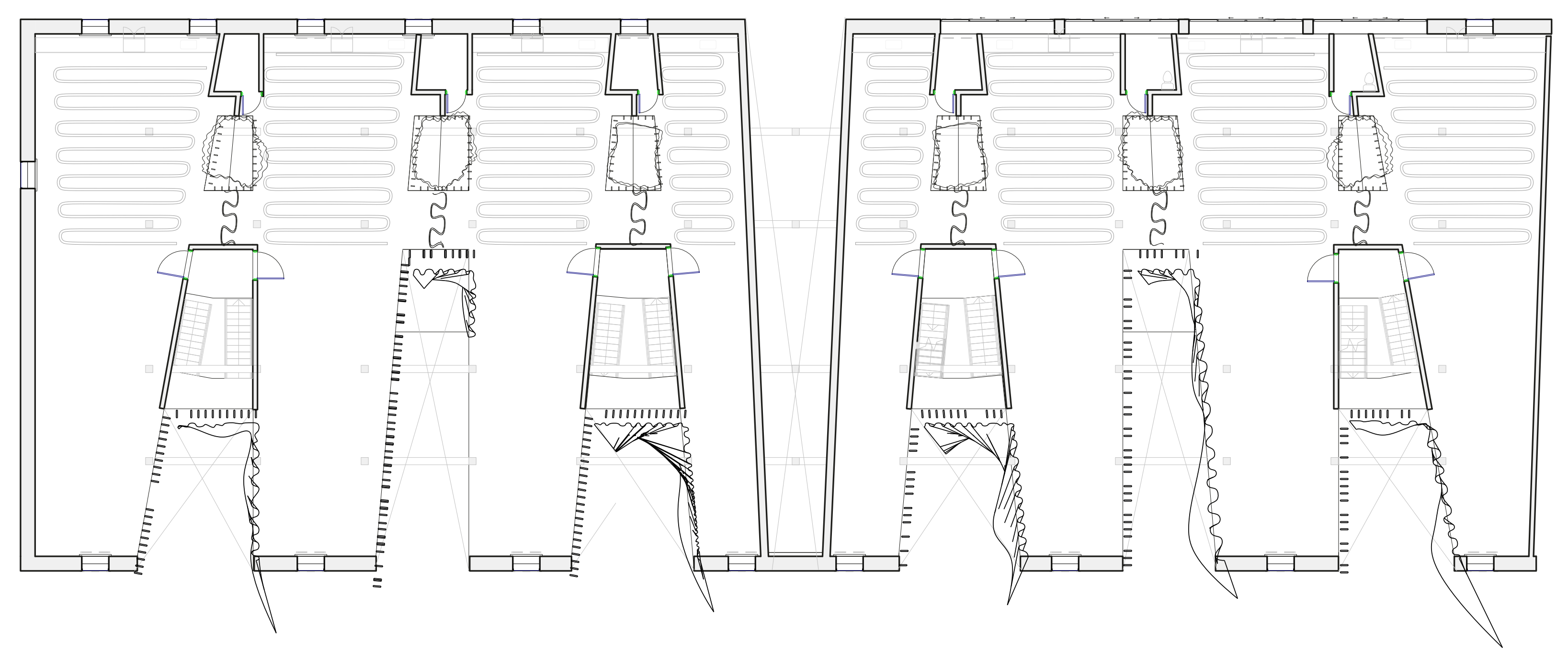

N 


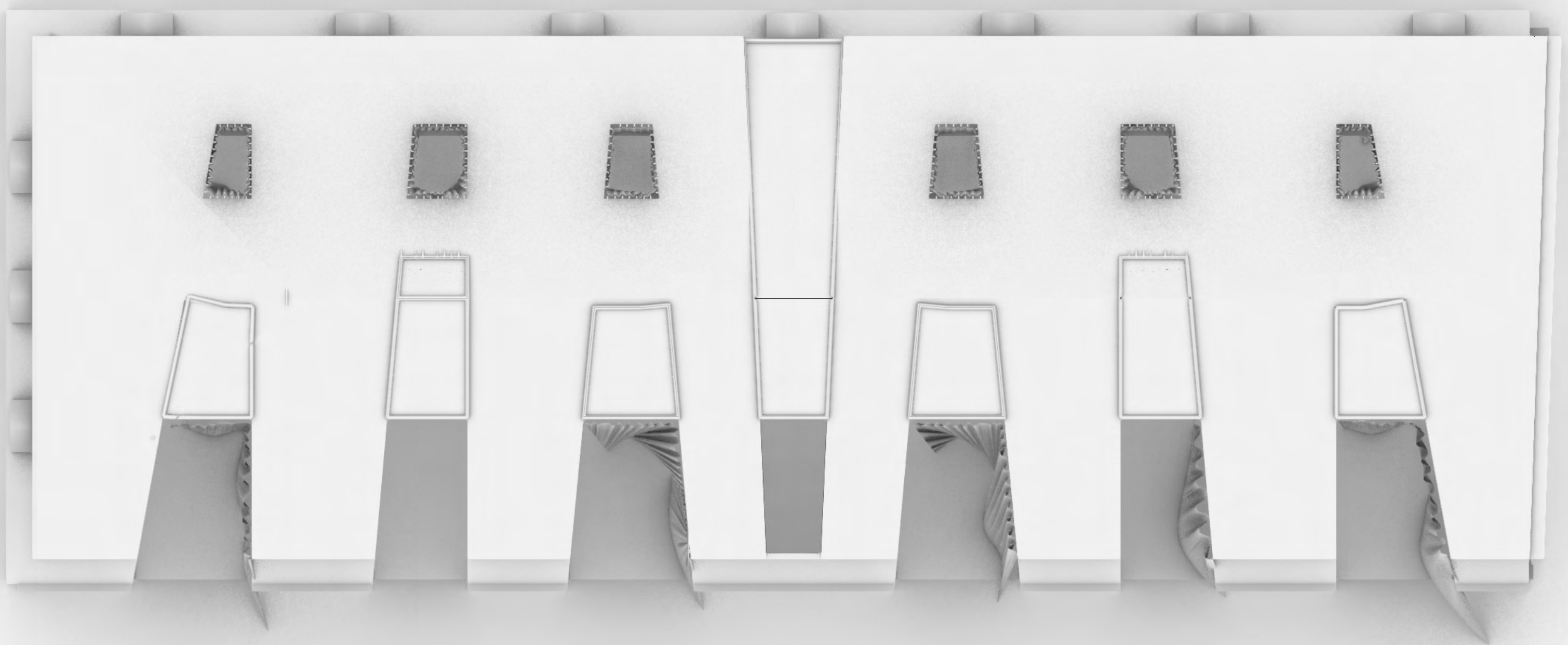




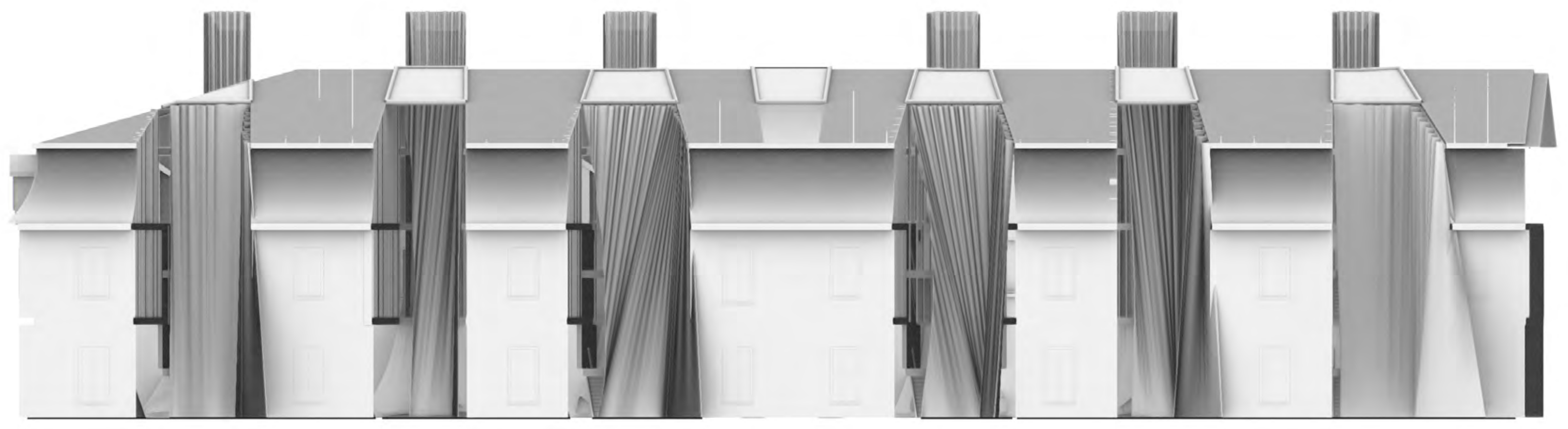



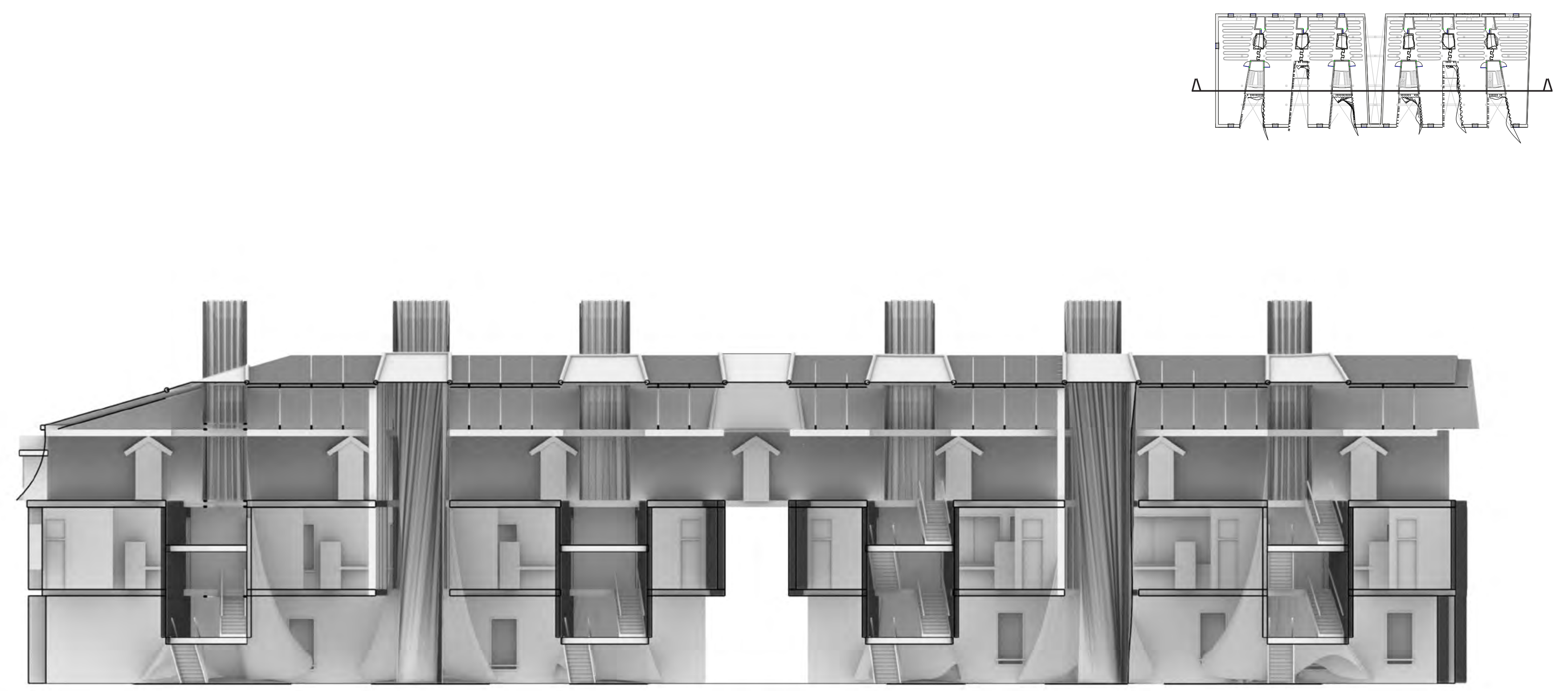

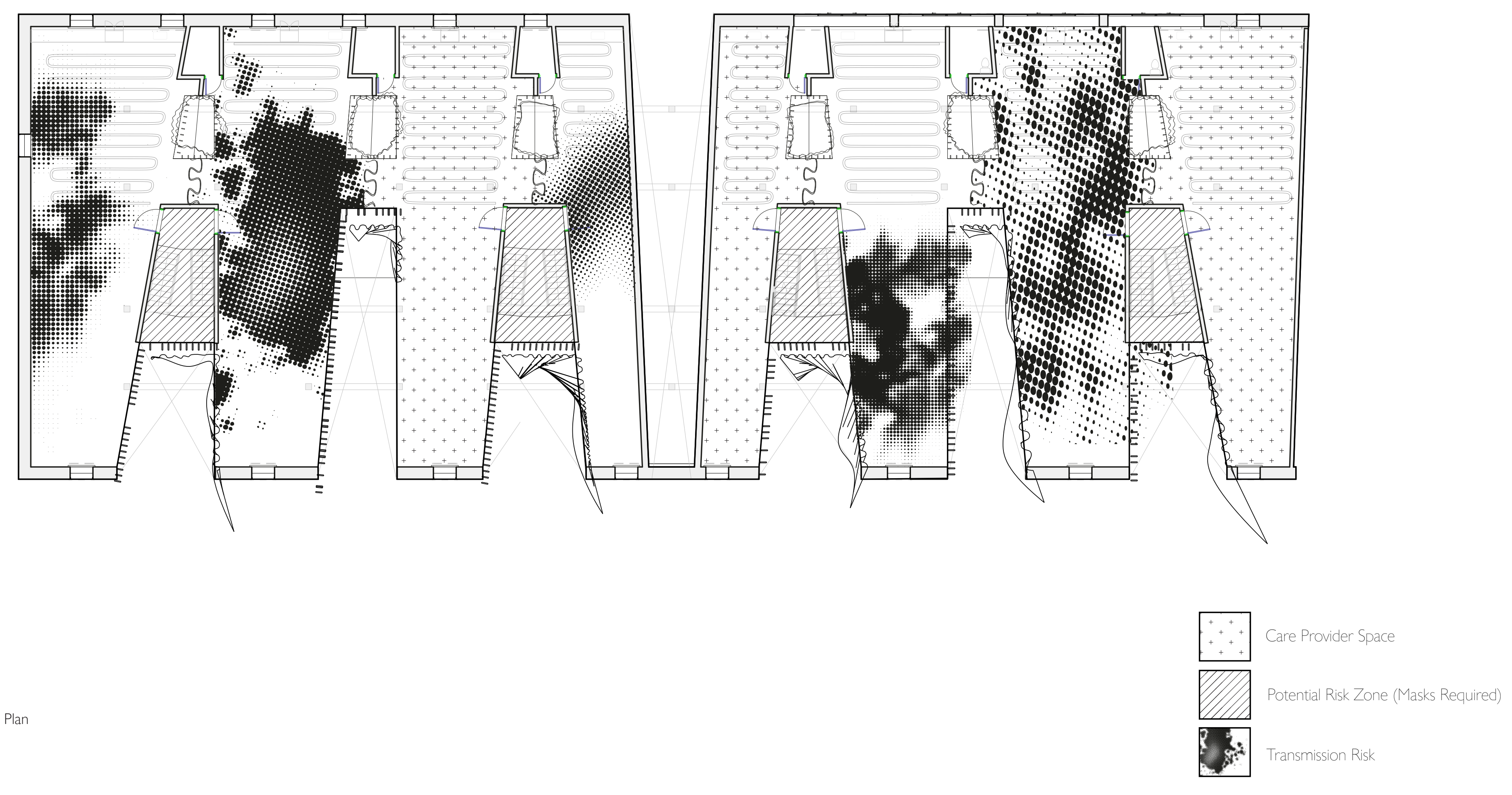


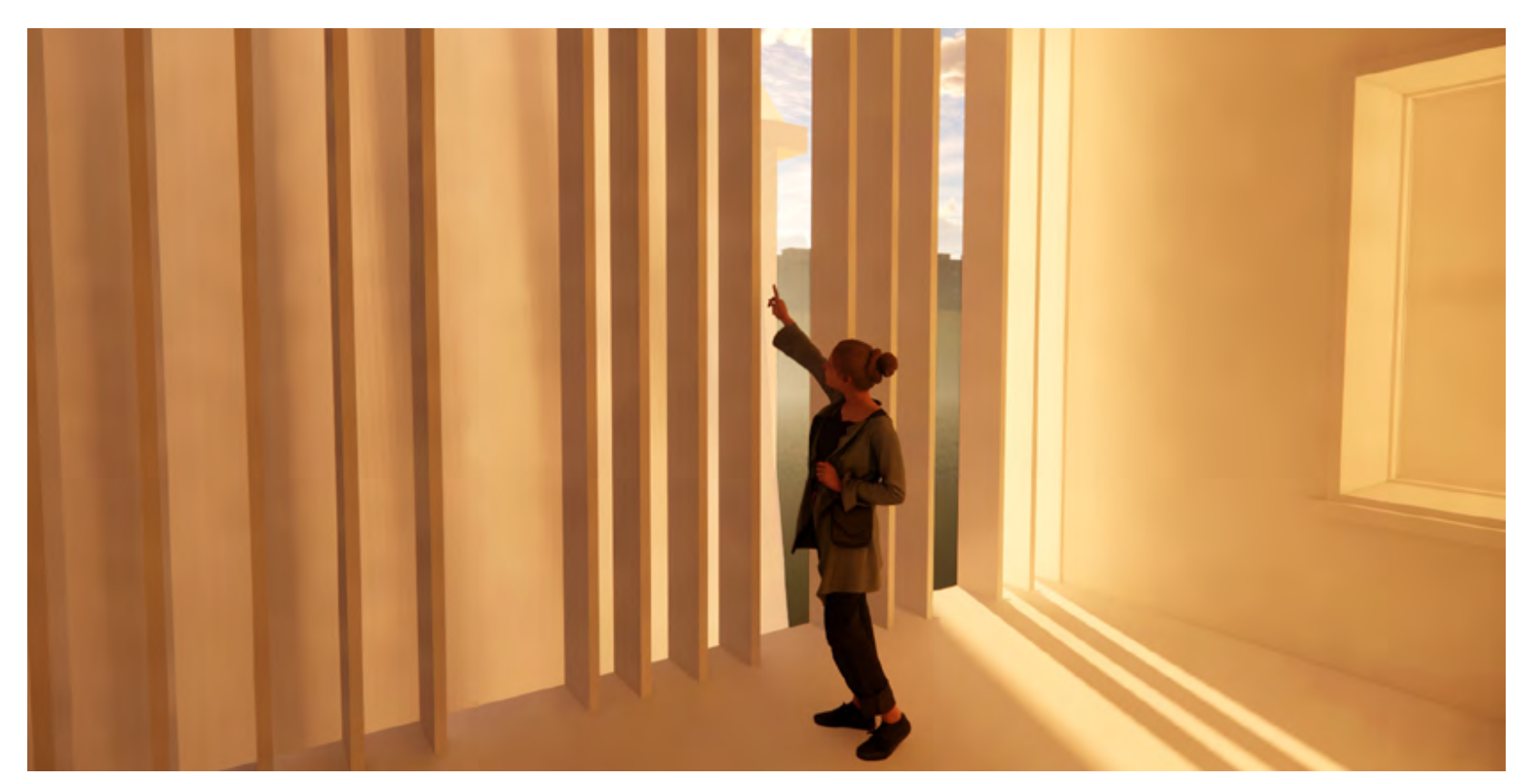

The 'filter vents' on the south façade of the building provide mediated exposure to external atmospheric and social conditions. Carefully perforated apertures are derived from the tank model studies performed as part of this project, and selectively permit air and light into the quarantine rooms. Reduced thermal insulation and increased porosity provide a balance against more thoroughly conditioned regions elsewhere in the rooms. In this way, the filter vents use thermal difference as a tool to expand the 'region of concern' for quarantined inhabitants.

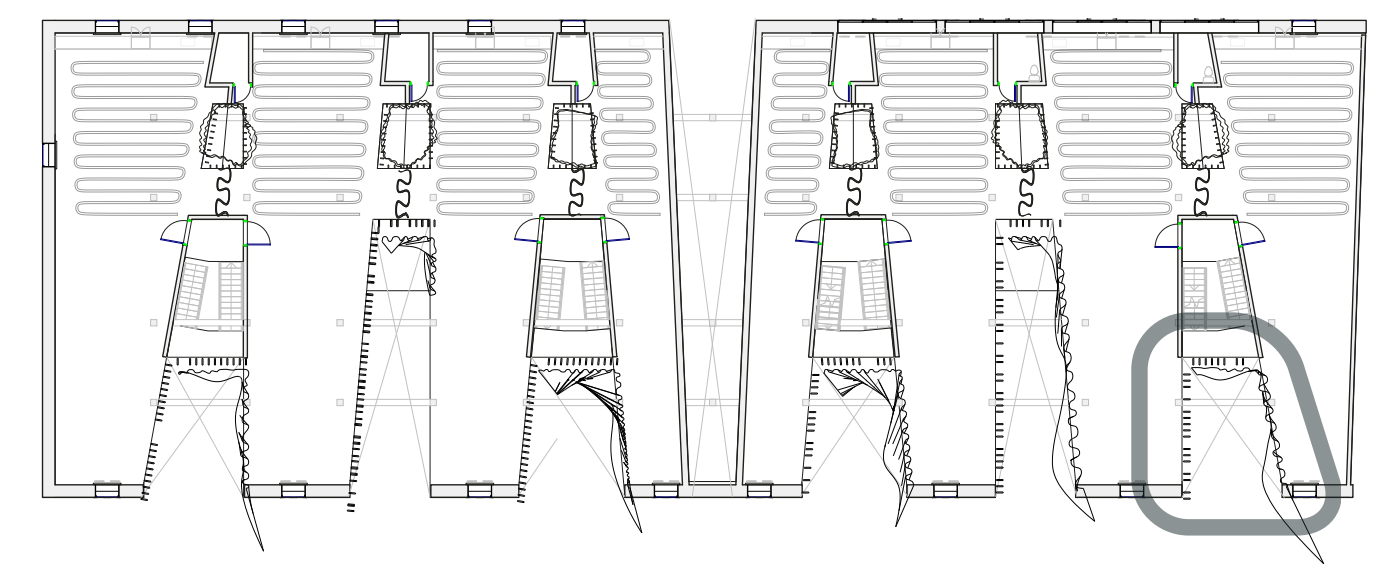




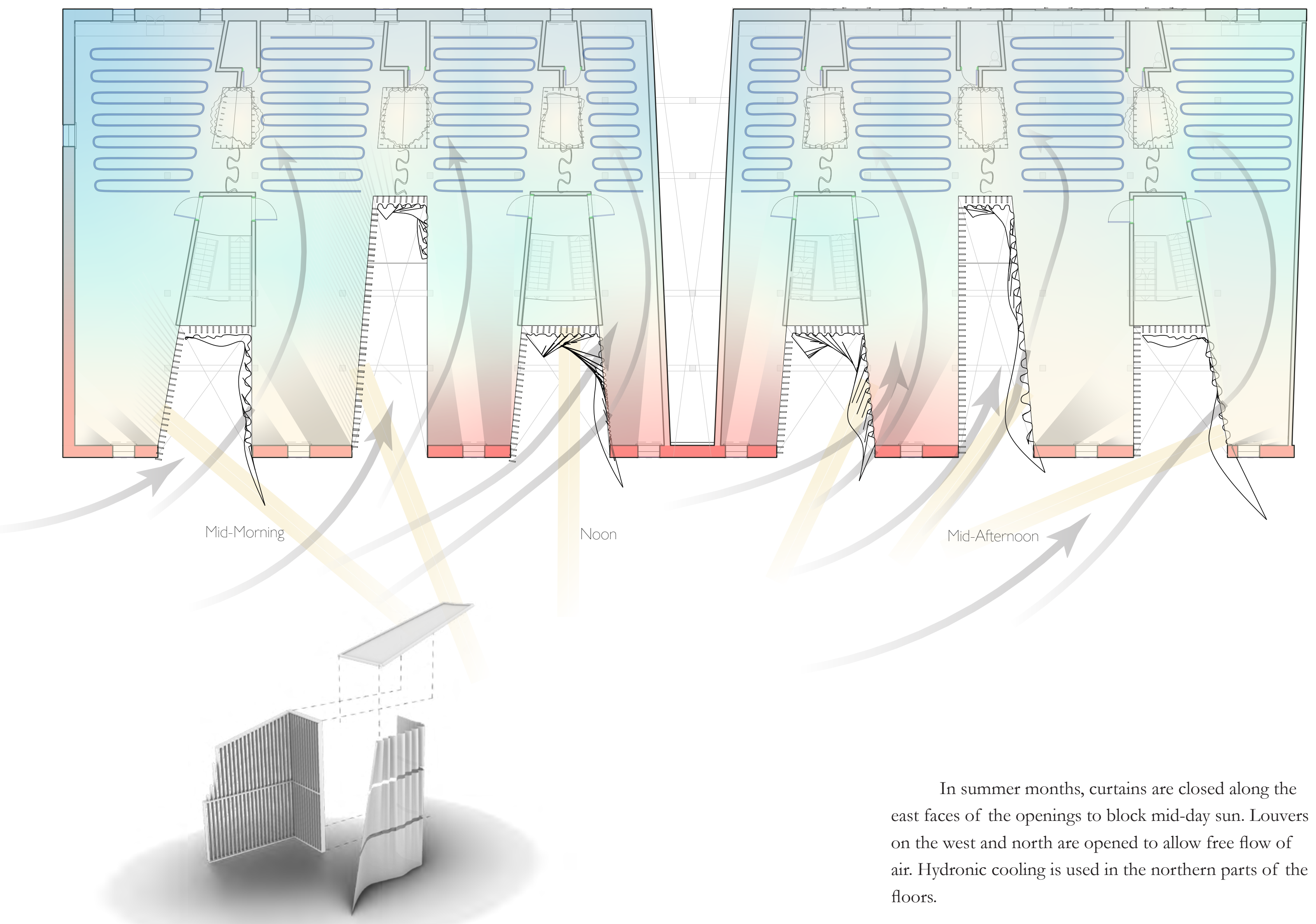




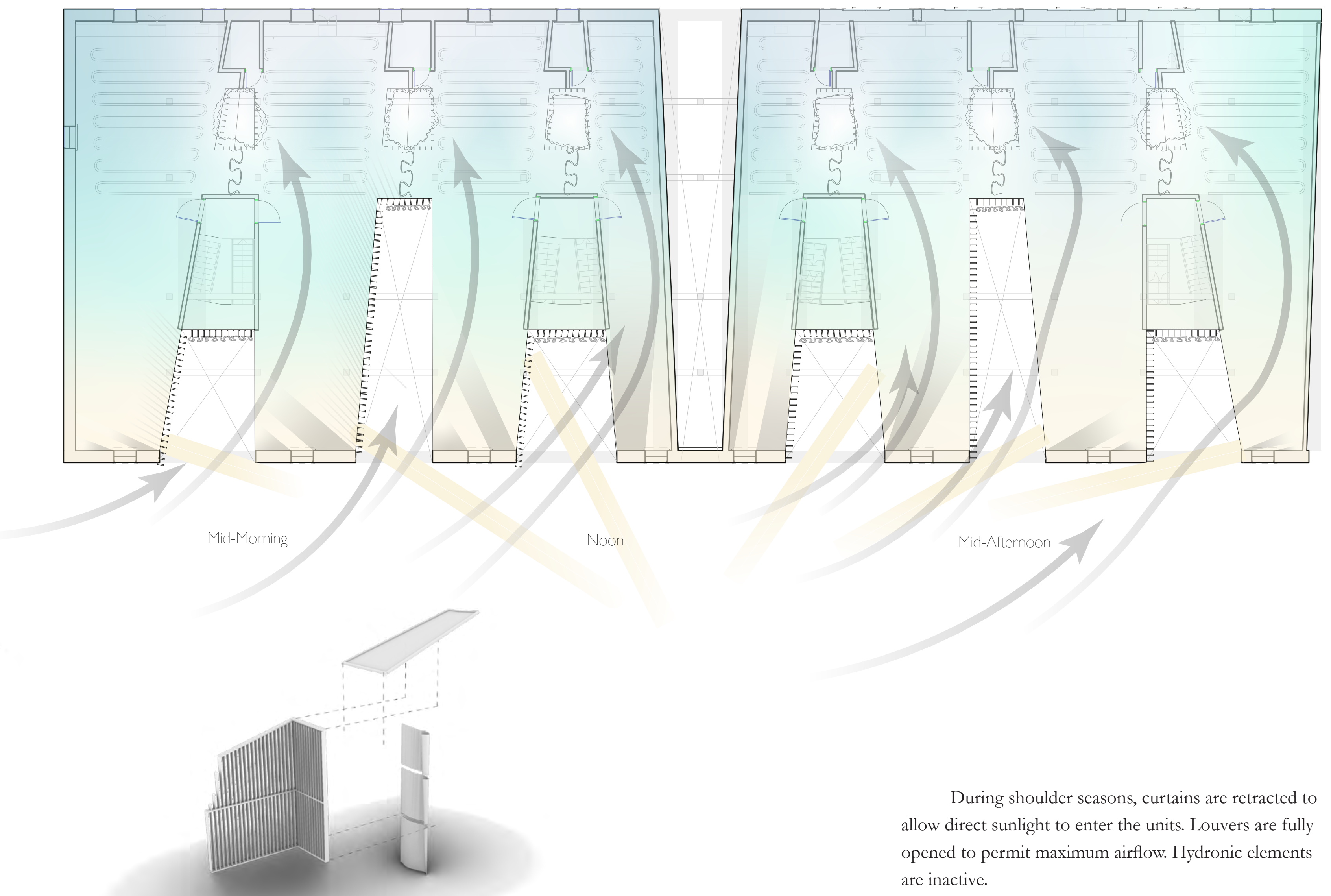




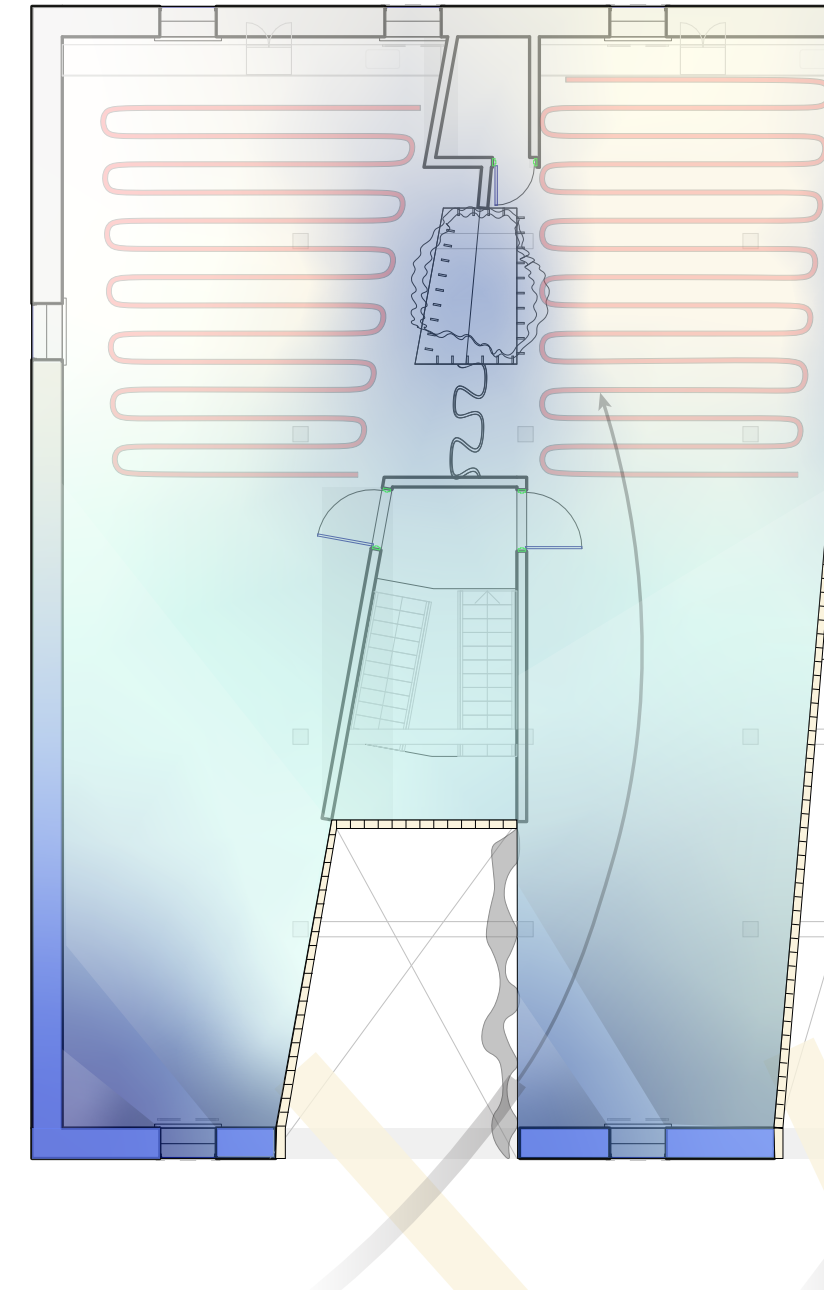

Sunrise

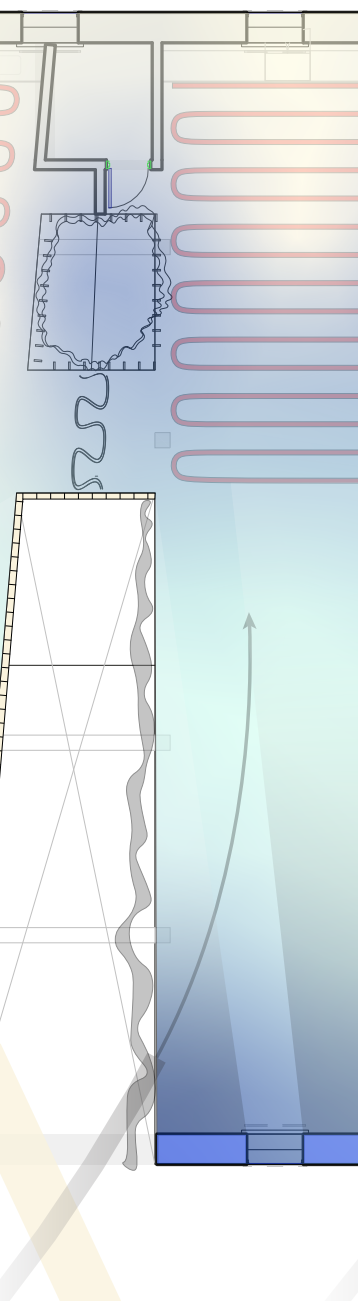

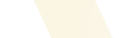

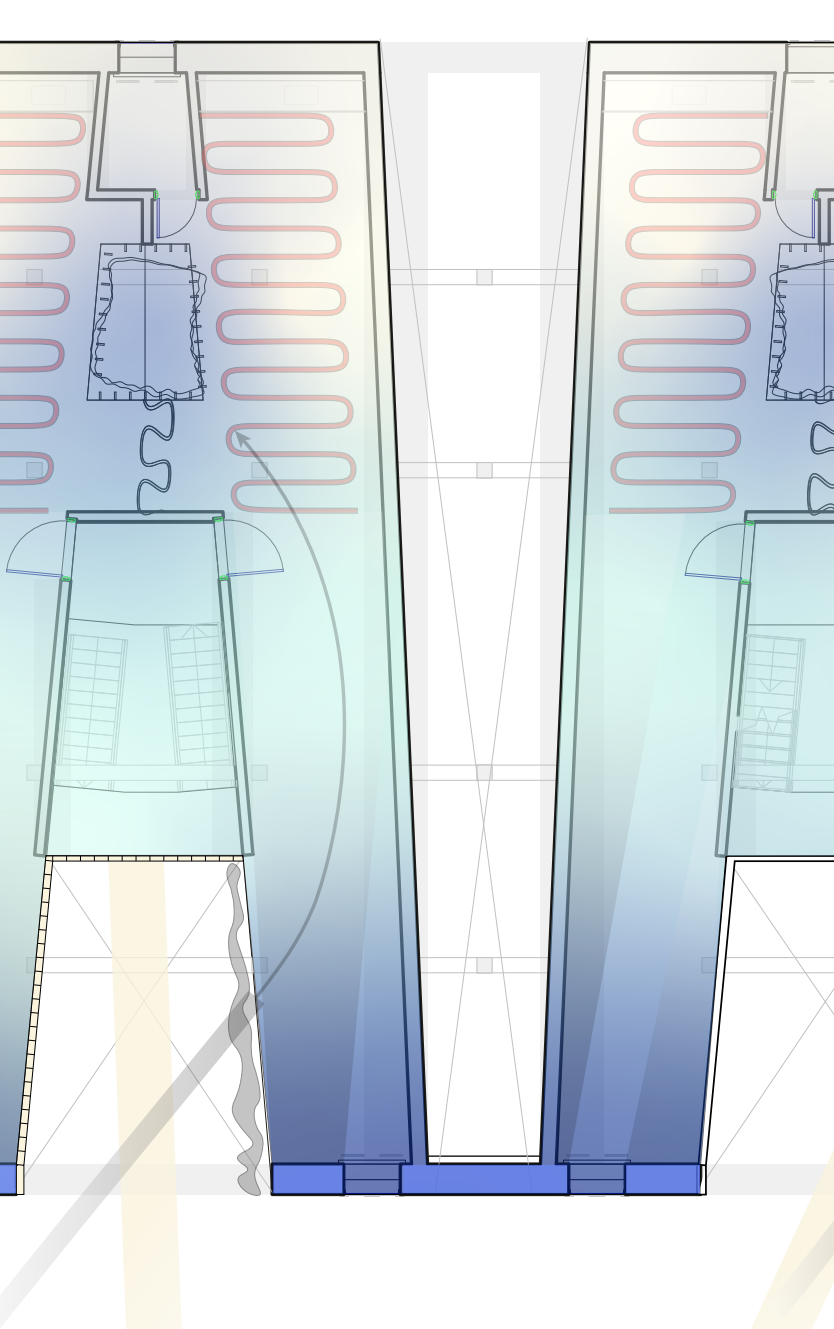

Noon

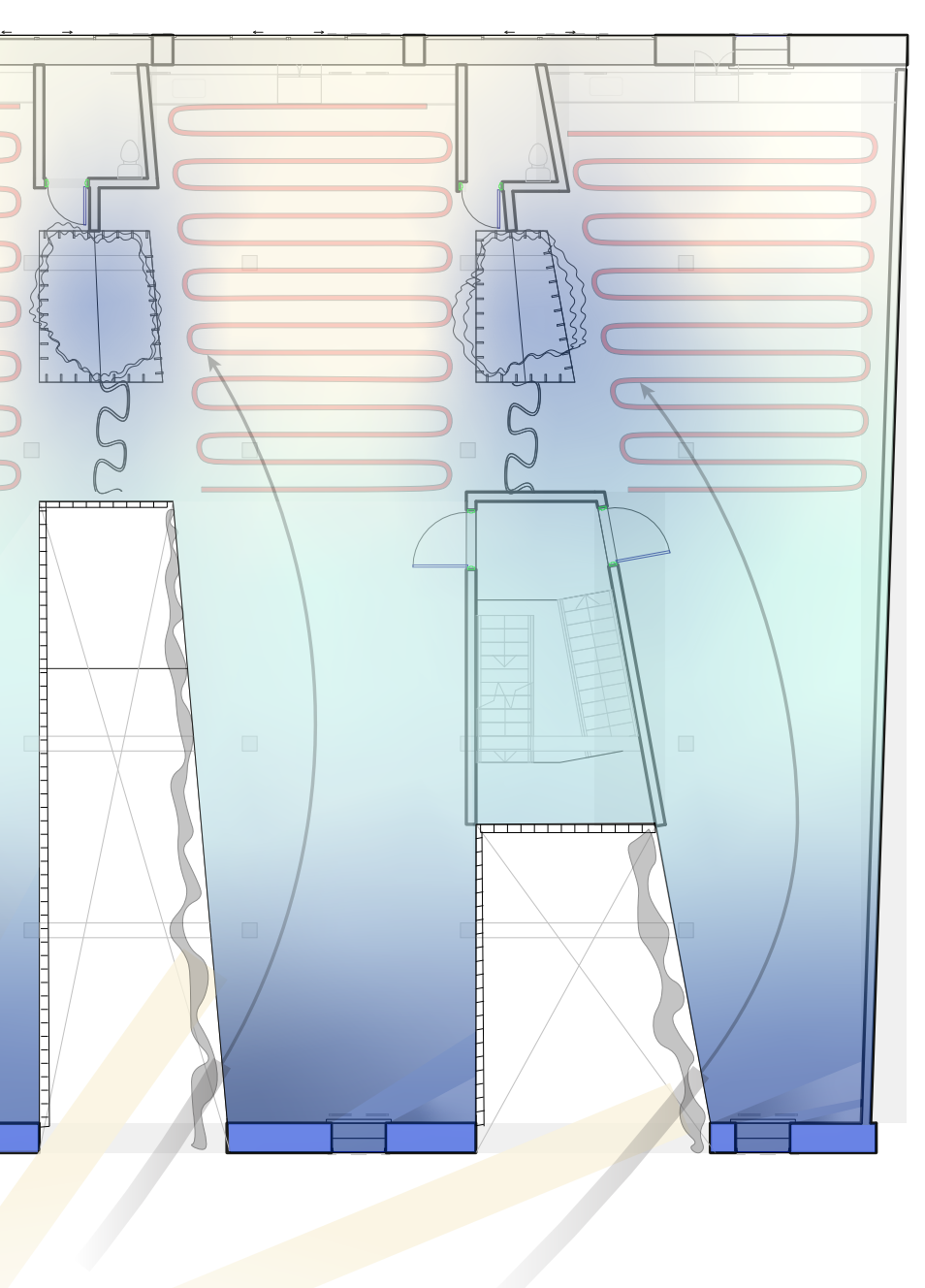

Sunset 


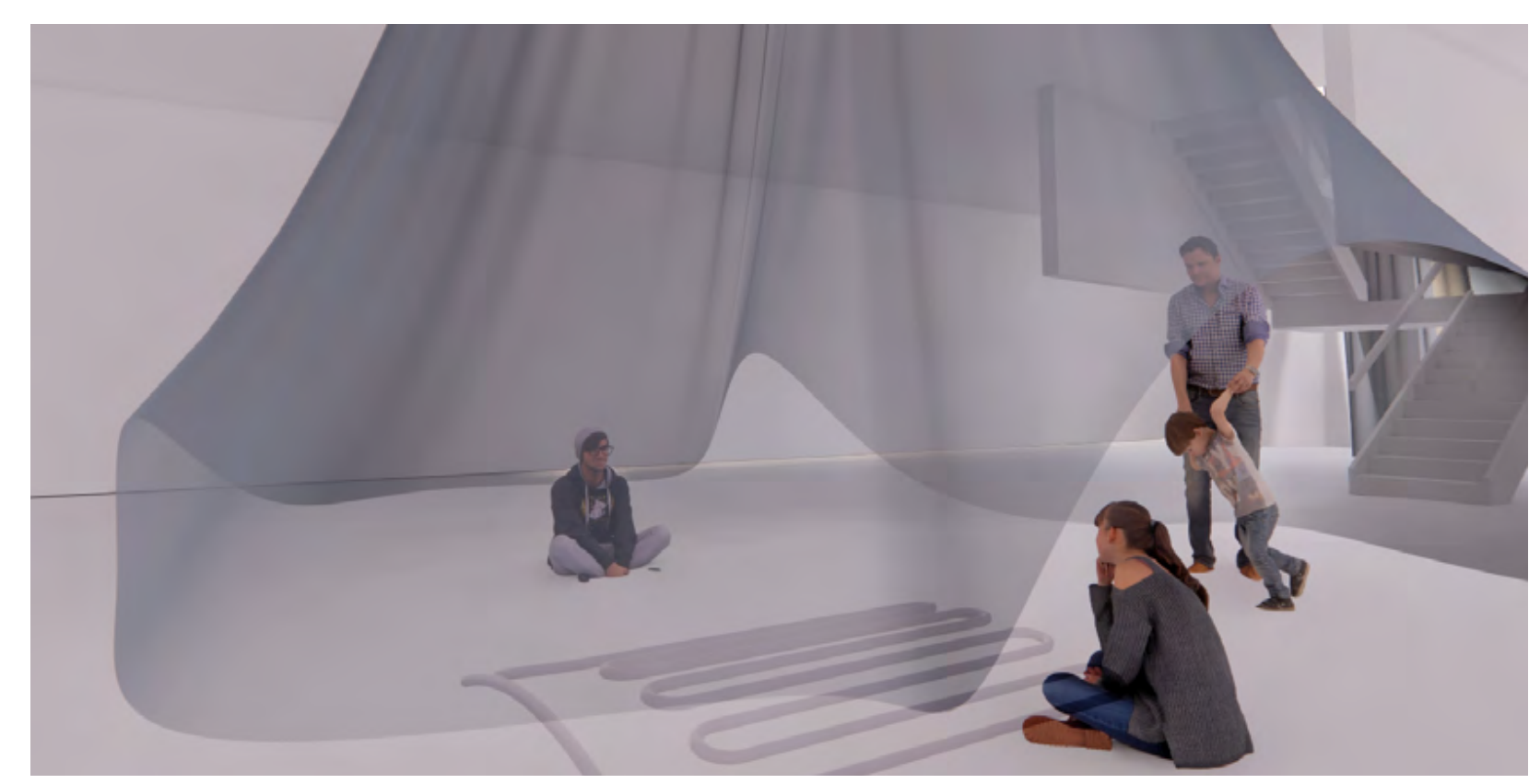

The 'Thermal Attractor Pad' provides an open-air social experience based on shared use of the thermal properties of a region heated using a hydronic loop in the floor slab. The pads are distributed through the otherwise unconditioned ground floor of the Hotel. As such they allow social congregation among members of different quarantine bubbles. An open mesh fabric is draped around the space to signal the thermal differential, and a slight depression in the slab permits comfortable seating. By shedding the building skin, the Thermal Attractor Pads enable fluid congregation without relying on rigid material.

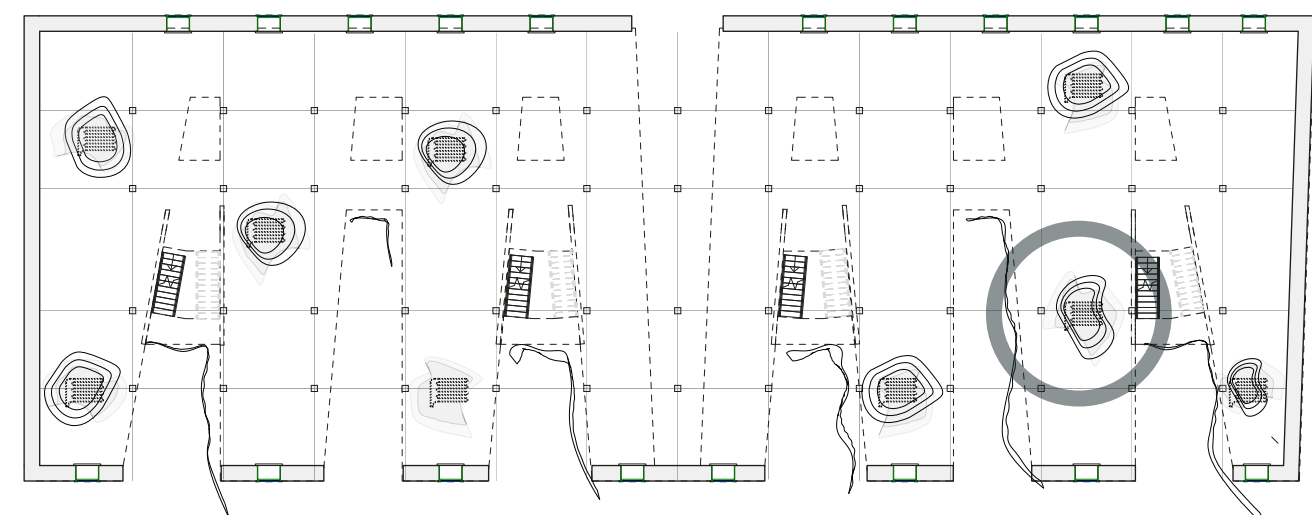




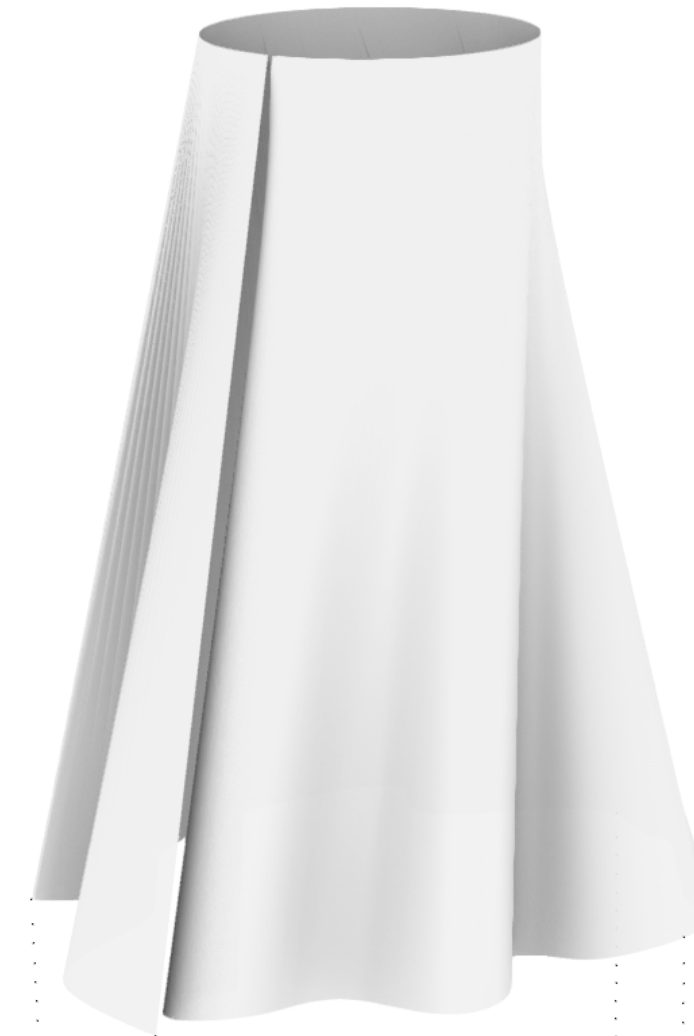

Filter Cloth Skirt

Concave Depression in Concrete Slab 


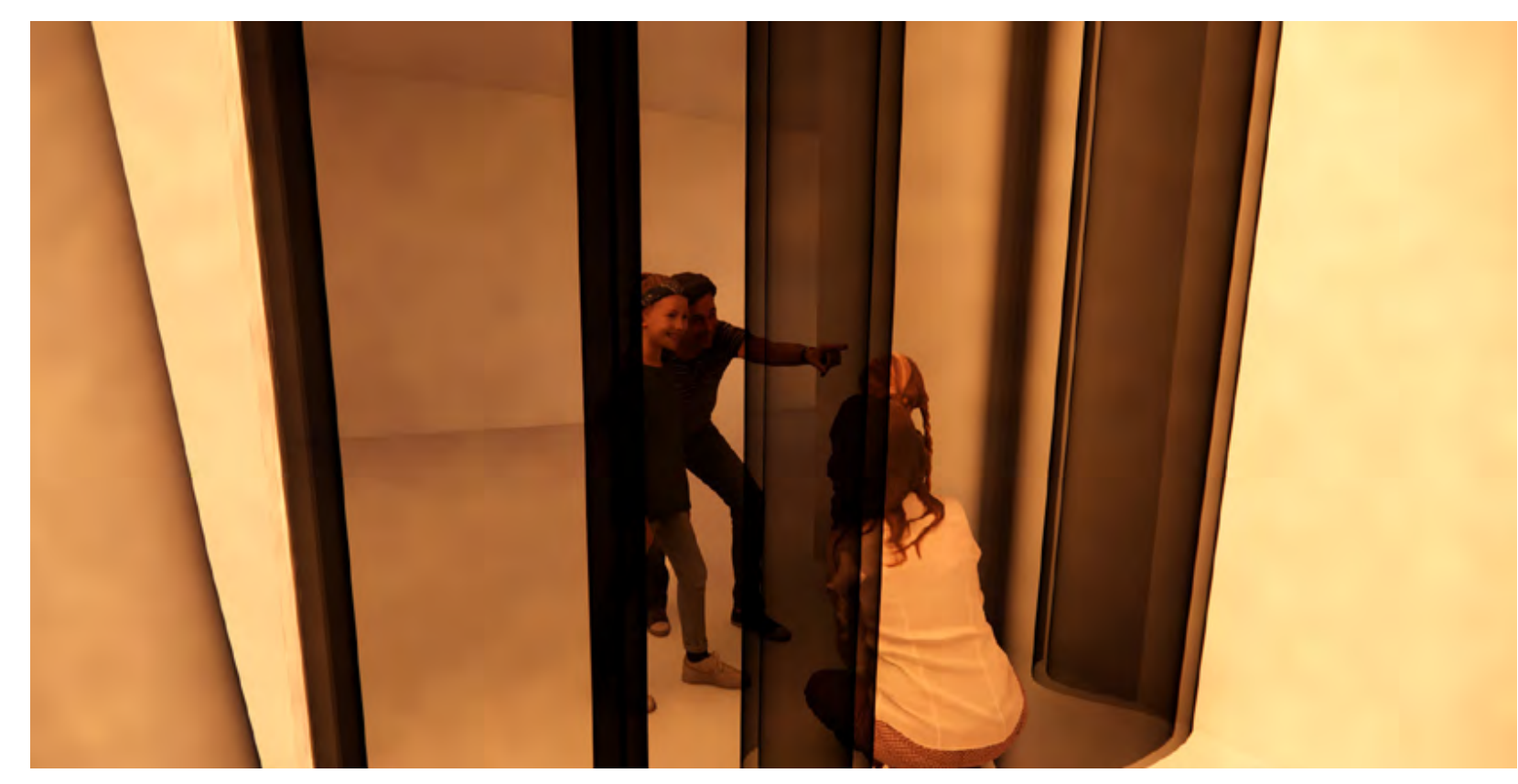

The 'Party! Wall' is composed of a fluid-filled double membrane which distributes heat from a hydronic element in the lower portion of the cavity. It permits attenuated awareness of those on the other side of the wall through translucency and flexibility. Its form is designed to yield slightly to the touch. As the sole source of heat for the quarantine rooms, it creates a social-thermal attractor which encourages interaction between co-isolated inhabitants while maintaining isolated airspaces. The 'Party! Wall' uses thermal difference as a tool to explicate the shifting boundaries of human topology.

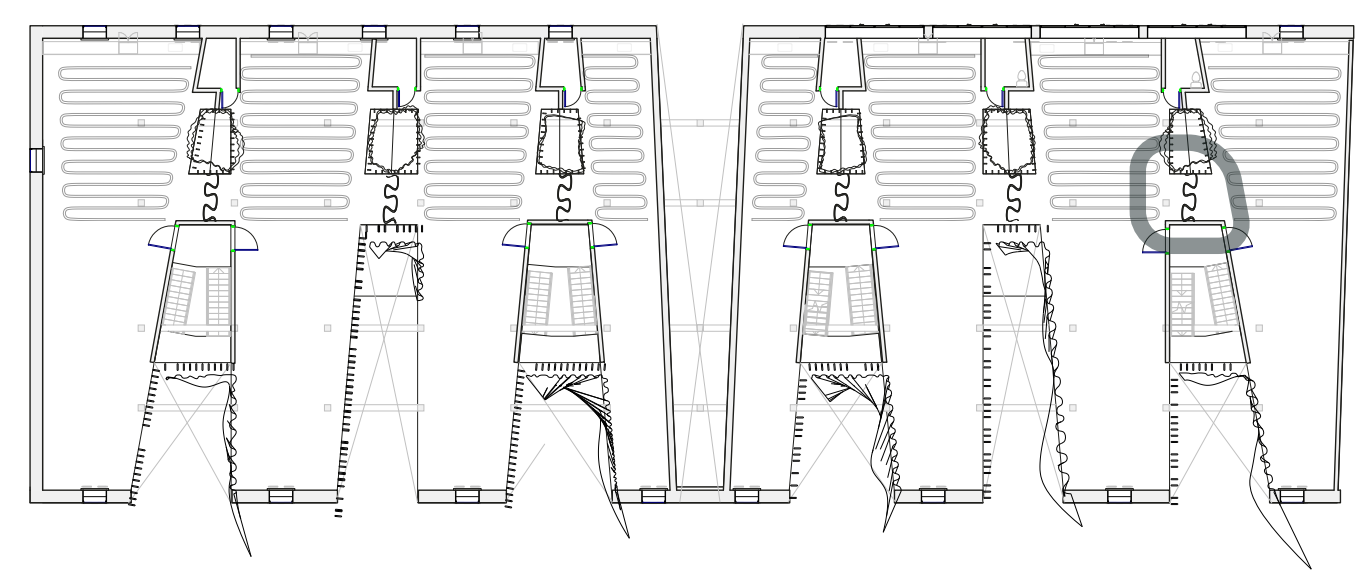




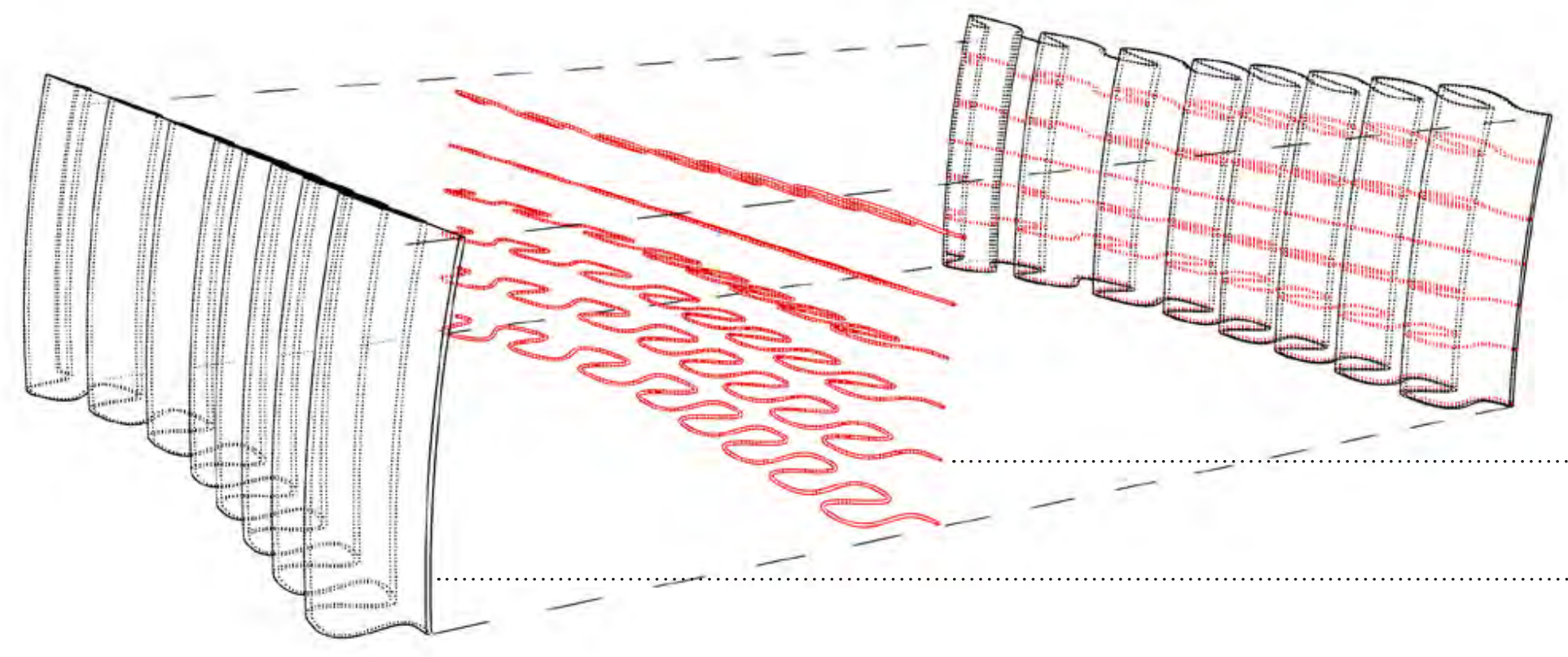




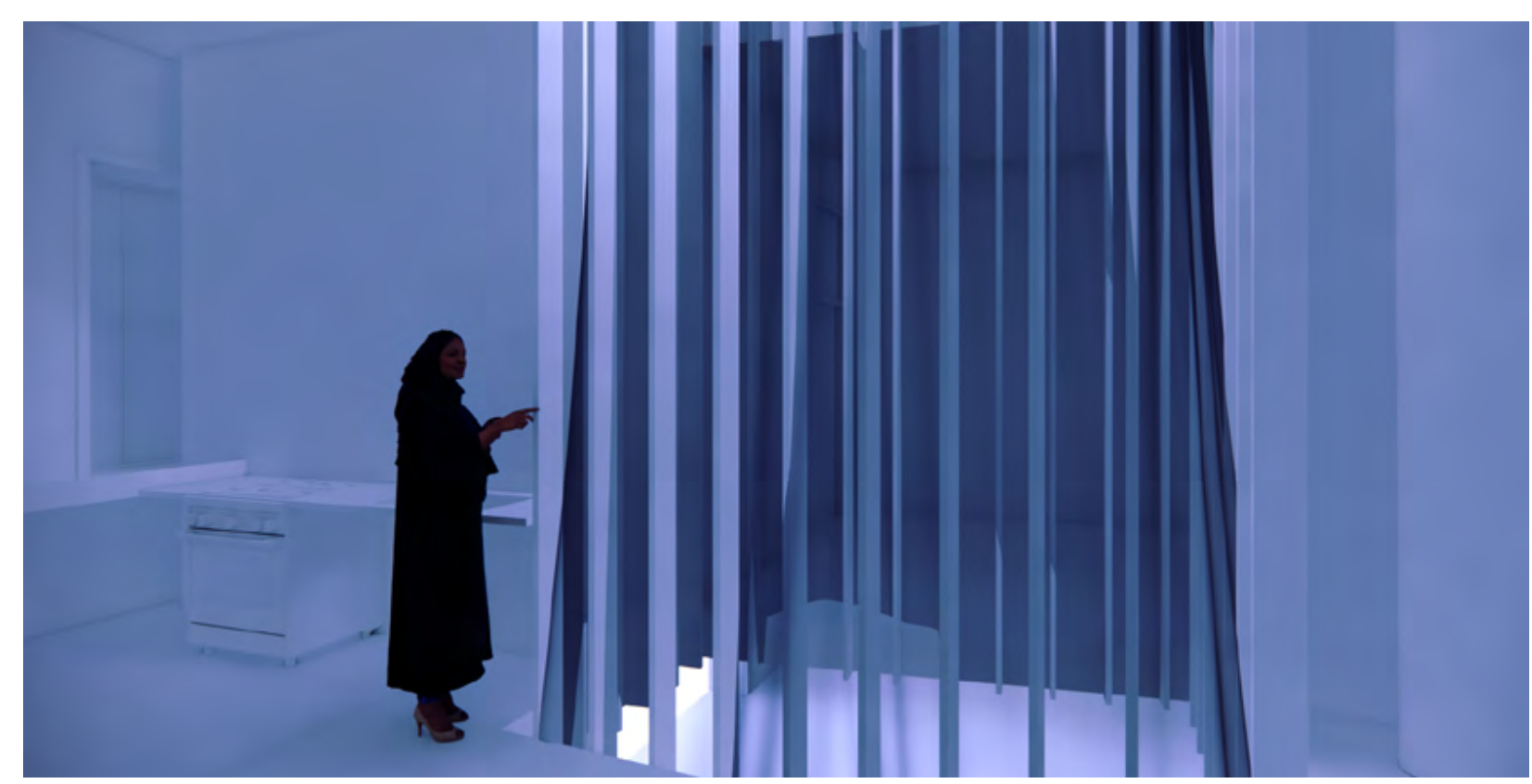

The 'Chimney Lung' is composed of vertical slats with a loose filter fabric hung within. It performs as a space of exhalation which extracts air from the quarantine rooms by means of the stack effect. An exposed portion of the chimney above the roof collects solar heat and draws cooler air from the unconditioned ground floor. The open mesh element allows air from adjacent quarantine rooms to be extracted. The mesh allows vertical (muted) transmission of sound, and views of spaces above and below. This exposure to elements outside the bubble disrupts the co-isolation condition of quarantine.

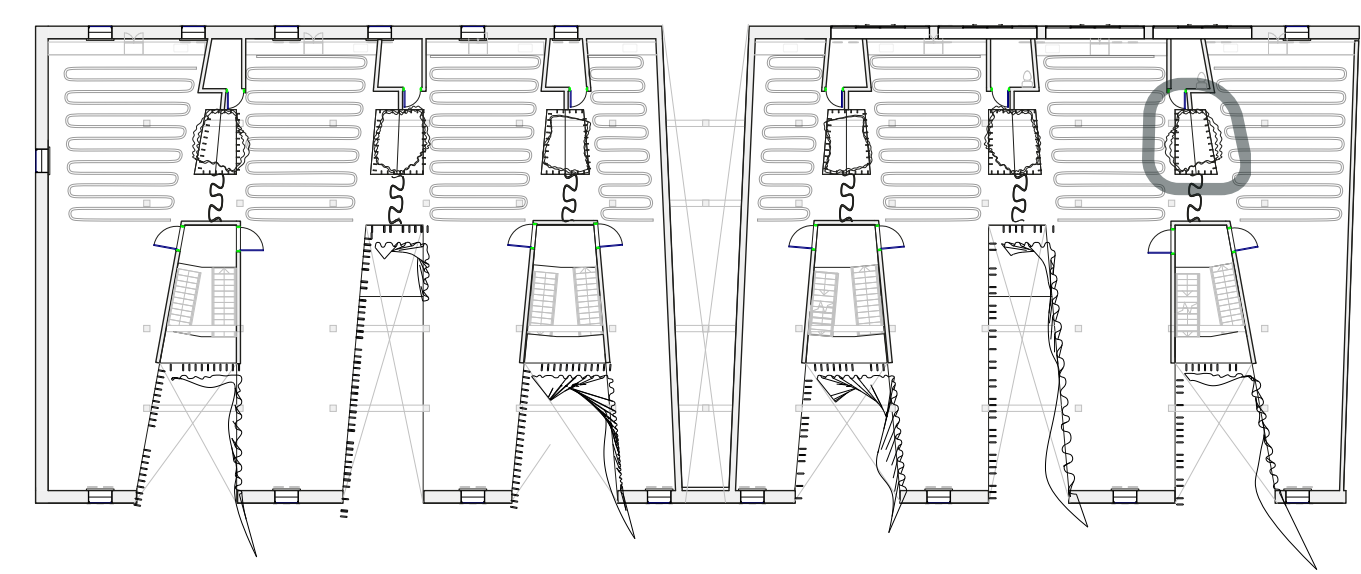




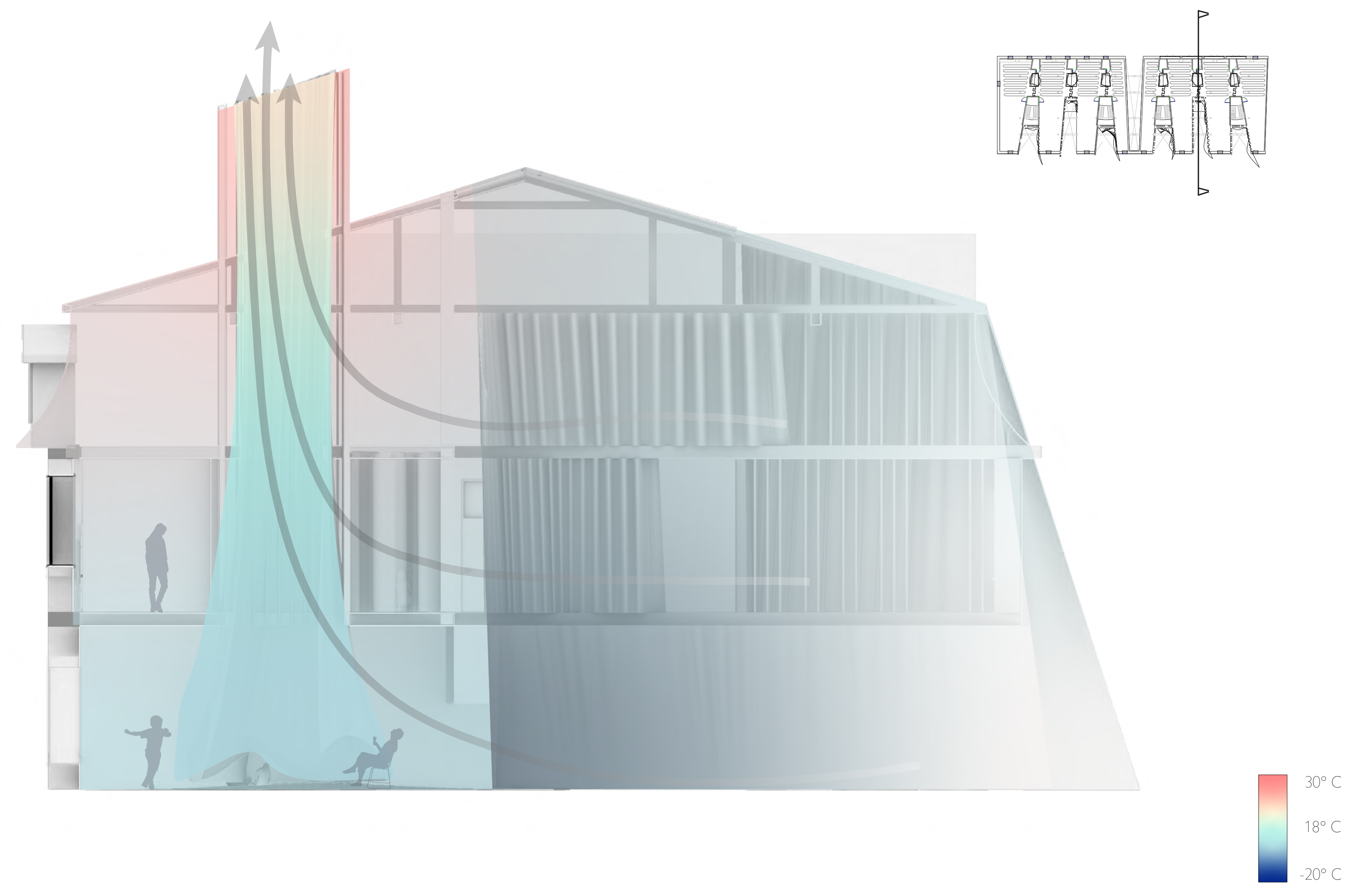




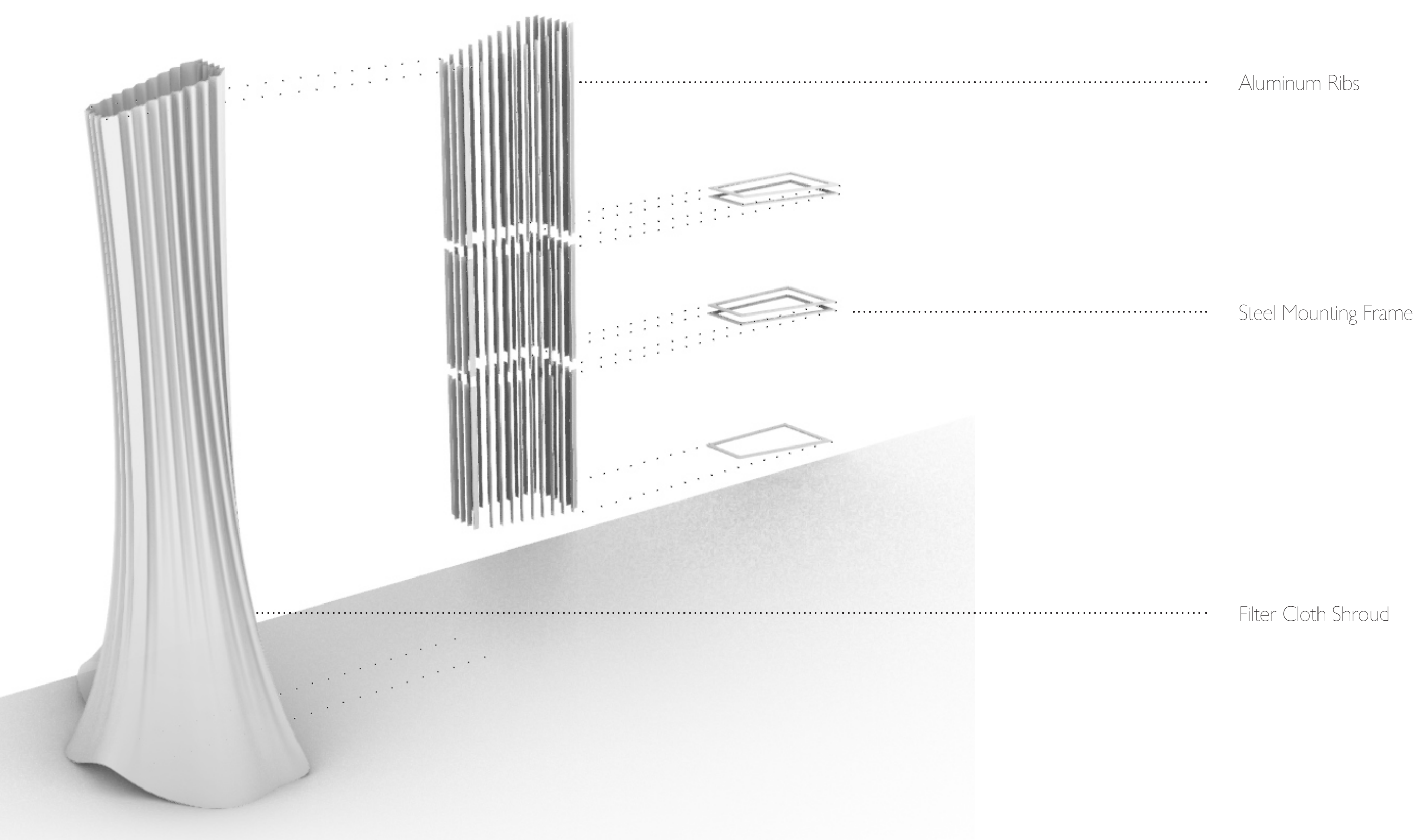


leads to a carefully crafted test environment (designed to be as specific as possible) was of limited use in this context. The results of the tank model experiments suggested manifold scalar

The development of this project was driven by a desire to uncover the phenomena which constitute interior space in relation to both social and environmental porosities. This admittedly expansive frame of inquiry was for me an opportunity to test representations of interior atmospheres though an experimental and intuitive methodology. The tank models were attractive for their power to surprise; when examined closely they appear to follow rules of interaction foreign to intuition or logic, yet from a distance still hew to principles of flow dynamics which can be repeatably exercised. While the models were useful in representing air dynamics, I was unable to extend their use to investigate social elements - a key component of the inquiry.

The ways in which the tank model experiments resonated with the theory continually surprised me. It was exhilarating to work between realms of inquiry (and their concomitant scales) using the common anchor of these experiments. This fuzzy mapping between material and theoretical approaches took me into unfamiliar ontological territory, an experience which rendered a profoundly altered view of design research. The design methodology familiar to architecture students - sketch, model, refine - is characterized by a comfort in knowing that the representations have a fixed relationship to the thing being designed (while sketching a section, the plane of the page firmly represents the plane of the cut through the project). The tank model experiments have an eerie ability to transcend this fixity. Similarly, the familiar scientific approach wherein a hypothesis interpretations that slipped outside even the most consciously fixed design intentions.

During the literature review for this project, I became keenly aware (and increasingly excited about) the breadth and depth of extant work covering the intersections of human space, thermal processes, and air. The work being done in this space is thrilling in its confrontation of assumptions long held in architecture. In particular, the work of Sean Lally was exciting to me in its renunciation of assumptions around the fixed material basis of architecture. A flow- and energy-informed view of building reduces architecture's elemental moves to the scale of the occupant, embracing the squishy weirdness of the human form and its micro-environments. The intimacy of this approach is far removed from the cold monumentality of capital-A Architecture as I had understood it.

The choice of air as the selected medium in the construction of the interior leaves out a broad array of processes and substances. This decision, along with other choices made along the way (notably site and program) was made with an acute awareness of paths not taken - an awareness that remains as the project comes to a close.

$\cdots$

In the spring of 2021, the end of the Covid-19 pandemic seems distant. The mechanisms of any return to normalcy seem tenuous and ill-defined. When that end does come, we may be surprised at the extent to which patterns of spatial 
negotiation and inhabitation do not readily return to their prepandemic states. Indeed, it becomes increasingly clear that while measures such as social distancing may be quick to recede, broader concerns around air quality and ventilation will remain. Sloterdijk notes that the weaponization of air through chemical warfare permanently altered our view of the medium. Similarly, the collective trauma of the last 14 months has dispelled any remaining notion of air's neutrality, as pathogenic transmission has been added to the array of potential airborne threats.

The reshaping of 'home' during the pandemic compressed activities that were once spatially disparate (work, socializing, exercise, etc) into spaces unsuited to these demands. Long periods of time spent in generic interior atmospheres deny occupants access to the content-rich relational field of 'outside' air, absent its thermal, olfactory, and flow characteristics. This phenomenon is stacked with enforced social exclusion through variously enforced conditions of quarantine. The concurrent absences of atmospheric and social content prompt for me an awareness of the interrelations of these phenomena; breathing air shared by other people is suddenly an illicit luxury to an extent which was previously unimaginable.

The design project undertaken in this thesis extends the occupation of the interior beyond established notions of inhabitation-through-exclusion, embracing elements and processes formerly outside the envelope. By embracing thermal gradients, the project prompts awareness of conditions outside. By maximizing airflow in all seasons while minimizing transmission risk, the project delivers content-rich air to the interior. By softening the walls between adjacent units, and by fostering a plane of interaction unbounded by material barriers, the project provides opportunities for interaction and care. In these ways, the project subverts the phenomenon of coisolation.

After the immediate threat of the pandemic has passed, we will emerge with a hunger for all that has been lost during quarantine. This project expresses a vision for enclosure designed to meet emergent needs for contact, interaction, and care unmet by current building practices.

Through the amplification of pre-existing tendencies towards atmospheric and social isolation, quarantine ruptures time scales and prompts awakened scrutiny of phenomena whose gradual change was previously invisible. Latent anxieties become explicit. This project embodies the hope that now is the time to challenge established understandings of private space and atmospheres.

Paul Jackson

May 2021, Ottawa 
Endnotes

Eiland, Howard (ed). "Walter Benjamin: Selected Writings, 3: 1935-1938”. Cambridge: Harvard

University Press, 2002 p. 38.

Evans, Robin. "Figures, Doors and Passages" in Translations from Drawing to Building Cambridge, Mass: MIT Press, 1997, 79.

3 Evans 85.

Evans 90-91.

Moe, Kiel, and Architectural Press Staff Princeton. Thermally Active Surfaces in Architecture, Princeton Architectural Press, 2010.

6 Mugerbeuer, Robert. "Anthropotechnology: Sloterdijk on Environmental Design and the FoamWorlds of Co-Isolation" 235.

7 Ibid 235.

Banham, Reyner. "A Home is Not a House", Art in America. 1965, volume 2, NY.

Banham 118.

10 Fuller, R. Buckminster. Operating Manual for Spaceship Earth. By R. Buckminster Fuller. Carbondale: Southern Illinois U. P., 1969. Print, 16.

11 Anker, Peder. "Viewing the Earth from Without or from Within" with Nina Edwards Anker, New Geographies 4. 2011, p. 90

12 Lally, Sean. The Air from Other Planets: A Brief History of Architecture to Come. Lars Muller Publishers, 2014, p.53-54.

13 Sloterdijk, Peter. Bubbles (trans. Wieland Hoban). Semiotext(e). 1998, 46.

14 Funcke, Bettina. "Against Gravity. Peter Sloterdijk mit Bettina Funcke" 2005 http://dev.autonomedia. org/node/4584.

15 Borch, Christian. 2008. "Foam architecture: managing co-isolated associations". Economy and Society 37 (4): 548-571.

16 Morin (Morin, M.-E.: The coming-to-the-world of the Human Animal, in: Sloterdijk Now, edited by: Elden, S., Polity Press, Malden, 77-95, 2012.p. 67)

17 Huib Ernste, The geography of spheres: an introduction and critical

assessment of Peter Sloterdijk's concept of spheres

18 Ibid 275.

Ibid 274.

Borch 552.

The term 'Co-isolation' is borrowed from Thom Mayne.

Sloterdijk, Peter. Bubbles (trans. Wieland Hoban). Semiotext(e). 1998, 59

Mugerauer, Robert. "Anthropotechnology: Sloterdijk on Environmental Design and the FoamWorlds of Co-Isolation", Architecture and Culture, 4:2, 227-248, DOI: 10.1080/20507828.2016.1178503, 2016, 238.

24 Moe, Kiel, and Architectural Press Staff Princeton. Thermally Active Surfaces in Architecture, Princeton Architectural Press, 2010.

25 Hawkes, Dean. "The Selective Environment: Environmental Design and Cultural Identity.'

26 Moe, Kiel, and Architectural Press Staff Princeton. Thermally Active Surfaces in Architecture, Princeton Architectural Press, 2010.

27 Heschong 44

Heschong 8.

Heschong 36

Heschong 37.

Lally 14 .

Lally 15

Lally 34 .

Rylan Higgins, Emily Martin \& Maria D. Vesperi (2020) An Anthropology of the COVID-19 Pandemic, Anthropology Now, 12:1, 2-6, DOI: 10.1080/19428200.2020.1760627
Bibliography

Anker, Peder. "Viewing the Earth from Without or from Within" with Nina Edwards Anker, New Geographies 4 2011, 89-94.

Banham, Reyner. "A Home is Not a House", Art in America. 1965, volume 2, NY:70-79.

Borch, Christian. 2008. "Foam architecture: managing co-isolated associations". Economy and Society 37 (4) $548-571$.

Eiland, Howard (ed). Walter Benjamin: Selected Writings, 3: 1935-1938. Cambridge: Harvard University Press, 2002.

Evans, Robin. "Figures, Doors and Passages" in Translations from Drawing to Building Cambridge, Mass: MIT Press, 1997.

Fuller, R. Buckminster. Operating Manual for Spaceship Earth. Carbondale: Southern Illinois U, 1969.

Funcke, Bettina. "Against Gravity. Peter Sloterdijk mit Bettina Funcke" 2005 http://dev.autonomedia.org/ node/4584.

Ernste, Huib. "The geography of spheres: an introduction and critical

assessment of Peter Sloterdijk's concept of spheres”. Geographica Helvetica. 73(4):273-284.

Hawkes, Dean. “The Selective Environment: Environmental Design and Cultural Identity.”

Higgins, Rylan, Emily Martin \& Maria D. Vesperi (2020). "An Anthropology of the COVID-19 Pandemic", Anthropology Now, 12:1, 2-6, DOI: 10.1080/19428200.2020.1760627

Lally, Sean. The Air from Other Planets: A Brief History of Architecture to Come. Lars Muller Publishers, 2014

Moe, Kiel, and Architectural Press Staff Princeton. Thermally Active Surfaces in Architecture, Princeton Architectural Press, 2010.

Morin, M.-E. "The coming-to-the-world of the Human Animal" Sloterdijk Now, edited by: Elden, S., Polity Press, Malden, 77-95, 2012.

Mugerauer, Robert. “Anthropotechnology: Sloterdijk on Environmental Design and the FoamWorlds of CoIsolation”, Architecture and Culture, 4:2, 227-248, DOI: 10.1080/20507828.2016.1178503, 2016

Sloterdijk, Peter. Bubbles (trans. Wieland Hoban). Semiotext(e). 1998.

Sloterdijk, Peter. Sphären III - Schäume, Plurale Sphärologie. Suhrkamp Verlag KG; Neuauflage. 2004 


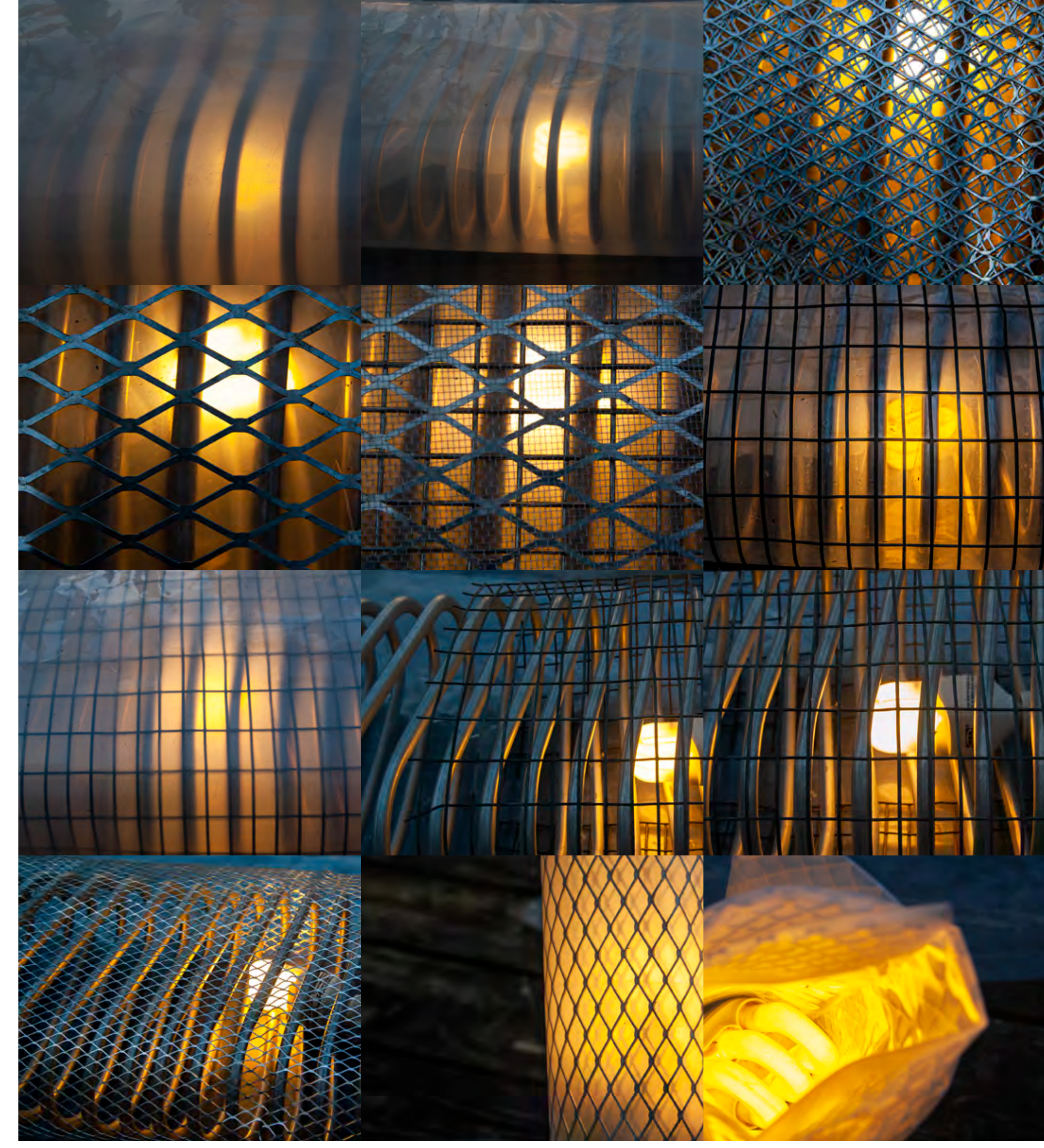

Contact Sheet 1: Enclosure Study 1/2 

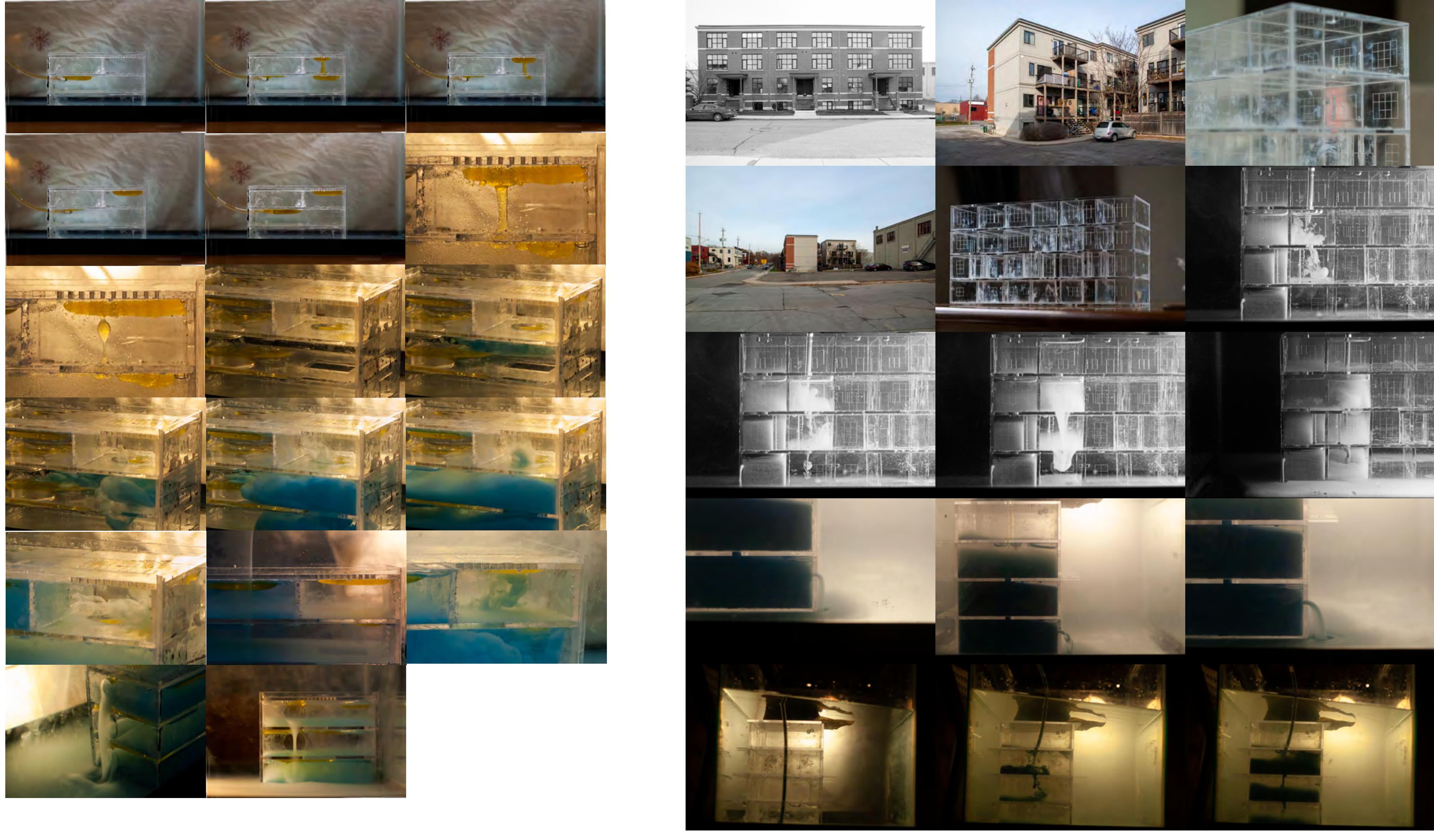
